\title{
Novel small molecule-derived, highly selective substrates for fibroblast activation protein (FAP).
}

An De Decker, ${ }^{\dagger}{ }^{\perp}$ Gwendolyn Vliegen, ${ }^{\ddagger \perp}$ Dries Van Rompaey, ${ }^{\dagger}$ Anke Peeraer, ${ }^{\dagger}$ An Bracke, ${ }^{\ddagger}$ Line Verckist, ${ }^{*}$ Ruth Geiss-Friedlander, Koen Jansen, ${ }^{+}$Koen Augustyns, ${ }^{+}$Hans De Winter, ${ }^{\dagger}$ Ingrid De Meester, ${ }^{\ddagger}$ Anne-Marie Lambeir, ${ }^{\ddagger}$ Pieter Van Der Veken. ${ }^{\dagger}$

${ }^{\dagger}$ Laboratory of Medicinal Chemistry (UAMC), Department of Pharmaceutical Sciences, University of Antwerp, Universiteitsplein 1, B-2610 Wilrijk (Antwerp), Belgium. ${ }^{*}$ Laboratory of Medical Biochemistry, Department of Pharmaceutical Sciences, University of Antwerp, Universiteitsplein 1, B-2610 Wilrijk (Antwerp), Belgium. "Laboratory of Cell Biology and Histology, Department of Veterinary Sciences, University of Antwerp, Universiteitsplein 1, B-2610 Wilrijk (Antwerp), Belgium. § Institut für Molekularbiologie, Universitätsmedizin Göttingen, Humboldtallee 23, D-37073 Göttingen, Germany.

${ }^{\perp}$ Contributed equally

\section{Contents:}

1) Synthetic protocols, spectral and analytical data for reported compounds.........................................2

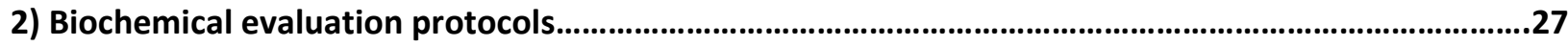

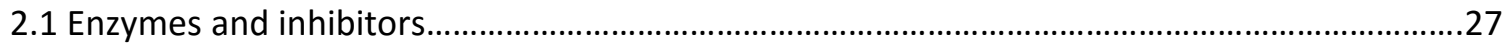

2.2 Kinetic characterization of AMC- and pNA-based molecules..................................................27

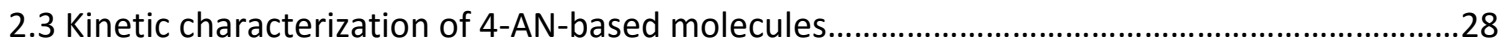

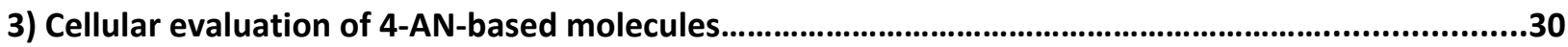

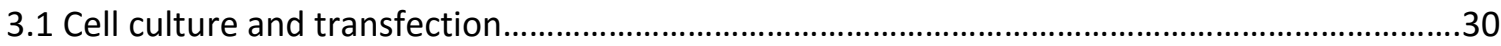

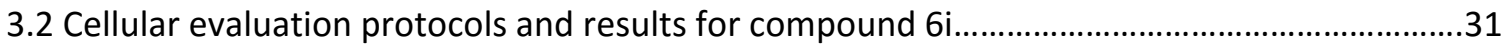




\section{1) Synthetic protocols, spectral and analytical data for reported molecules.}

Unless stated otherwise, laboratory reagent grade solvents were used. Reagents were purchased from SigmaAldrich, Acros organics, Apollo scientific, $\mathrm{TCl}$ or Fluorochem and were used without further purification, unless mentioned otherwise. Characterisation of compounds was done with ${ }^{1} \mathrm{H}$ NMR, ${ }^{13} \mathrm{C}$ NMR, LC-MS and HRMS for key products. ${ }^{1} \mathrm{H}$ NMR spectra were recorded on a $400 \mathrm{MHz}$ Bruker Avance III nanobay spectrometer with ultrashield. Chemical shifts are reported in ppm and coupling constants are in $\mathrm{Hertz}(\mathrm{Hz})$. Purity of the compounds was verified by using an HPLC system. In this case: UPLC: Waters acquity H-class UPLC system coupled to a Waters TQD ESI mass spectrometer and a Waters TUV detector. A Waters acquity UPLC BEH C18 $1.7 \mu \mathrm{m}$ particle size, $2.1 \times 50 \mathrm{~mm}$ column was used. Solvent A: water with $0.1 \%$ formic acid, solvent B: Acetonitrile (MeCN) with $0.1 \%$ formic acid. The wavelength for UV detection was $254 \mathrm{~nm}$ unless mentioned otherwise. High-Resolution Mass Spectrometry experiments were performed on a QTOF-2TM instrument (Micromass, Waters). If necessary, flash purification was performed on a Biotage "ISOLERA One flash system equipped with an internal, variable dual-wavelength diode array detector (200 - $400 \mathrm{~nm}$ ). For normal phase (NP) purification, SNAP cartridges (10 - $100 \mathrm{~g}$; flow rate: $10 \mathrm{ml} / \mathrm{min}$ - 50 $\mathrm{ml} / \mathrm{min}$ ) were used. Reversed phase (RP) purifications were performed on KP-C18 cartridges (12 - $30 \mathrm{~g}$; flow rate: 10 $\left.\mathrm{mL} \cdot \mathrm{min}^{-1}-15 \mathrm{~mL} \cdot \mathrm{min}^{-1}\right)$. Dry sample loading was done in Self Packing Samplet ${ }^{\bullet}$ cartridges using silica or Celite 545, for respectively NP- and RP-purifications. Used gradients are variable for every purification.

All final compounds reported in this publication were determined to have a purity of $\geq 95 \%$.

A number of synthetic procedures were used during the preparation of multiple compounds. These are referred to as 'General procedures' The individual General procedures (A-G) are defined hereunder.

\section{General procedure A:}

The carboxylic acid (1.4eq.) was dissolved in DCM:THF (1:1) and ghosez reagent (1.4eq.) was added to the reaction mixture. After 15 minutes a solution of the amine (1eq.) and triethylamine (1eq.) in DCM was added to reaction mixture and the reaction was left stirring for an overnight at room temperature. After reaction completion, the volatiles were evaporated and a minimal amount of acetone was added until precipitation occurred. The formed precipitate was filtered of and washed with a minimal amount of water.

\section{General procedure B:}

To a cooled $\left(0^{\circ} \mathrm{C}\right)$ solution of the carboxylic acid (1eq.) in dry DCM $(0.2 \mathrm{M})$, triethylamine (2eq.) was added. The reaction mixture was placed under an Ar-atmosphere and isobutylchloroformate (1eq.) was added in a dropwise manner. After 30 minutes 4-aminonaphthalen-1-ol hydrochloride $(3,1$ eq.) was added to the reaction mixture, the reaction was brought to room temperature and left stirring overnight. After reaction completion the volatiles were evaporated under reduced pressure. The residue was redissolved in EtOAc and washed with a $1 \mathrm{M} \mathrm{HCl}$ solution (3*), 
brine $\left(3^{*}\right)$, a concentrated $\mathrm{NaHCO}_{3}$ solution $\left(3^{*}\right)$ and brine $\left(3^{*}\right)$. The organic phase was dried over sodium sulphate, filtrated and evaporated.

\section{General procedure C:}

The Boc-protected proline analogue (1eq.) was dissolved in DCM (0.1 M) and a $4 \mathrm{M}$ solution of $\mathrm{HCl}$ in dioxane (8eq.) was added to the reaction mixture and the reaction was left stirring overnight at room temperature. After reaction completion, a minimal amount of diethylether was added until precipitation occurred. The formed precipitate was filtered off and was dried in vacuo.

\section{General procedure D:}

To a solution of the Boc-protected amine (1eq.) in DCM, TFA (20eq.) was added dropwise. The reaction mixture was left stirring at room temperature for 1 hour. After reaction completion the volatiles were evaporated and the crude was washed with diehyl ether $\left(3^{*}\right)$.

\section{General procedure E:}

To a solution of the Boc-protected amino acid (1.1eq.) in dry DCM (0.1 M), triethylamine (3eq.) was added, followed by the addition of the proline analogue (1eq.) and 1-propanephosphonicacidcyclicanhydride solution in EtOAc (50\% wt) (1.1eq.). The reaction was left stirring for 30 minutes at room temperature. After reaction completion the volatiles were evaporated under reduced pressure. The residue was redissolved in EtOAc and washed with water $\left(3^{*}\right)$, conc. $\mathrm{NaHCO}_{3}\left(3^{*}\right)$ and brine $\left(3^{*}\right)$. The organic phase was dried over sodium sulphate, filtered of and further concentrated under reduced pressure.

\section{General procedure F:}

To a solution of the carboxylic acid (1.1eq.) in dry DCM, DIPEA (2eq.) and HATU (1.1eq.) were added. After 30 minutes the primary amine (1eq.) was added to the reaction mixture and the reaction was left stirring overnight at room temperature. After reaction completion the volatiles were evaporated under reduced pressure. To the residual oil, water was added upon precipitate formation. The precipitate was filtered of and dried further in vacuo.

\section{General procedure G:}

A solution of the carboxylic acid (1.1eq.) in dry DMF was placed under an Ar-atmosphere at $0{ }^{\circ} \mathrm{C}$. DIPEA (2eq.) and HATU (1.1eq.) were added to the reaction mixture, directly followed by the addition of the proline analogue (1eq.). The reaction was brought to room temperature and was left stirring overnight at room temperature. After reaction completion, water was added and the mixture was extracted with EtOAc $\left(3^{*}\right)$. The combined organic phases were 
washed with water $\left(3^{*}\right)$, dried over sodium sulphate, filtrated and further concentrated under reduced pressure resulting in the crude product. Further purification by NP-flash chromatography: EtOAc $\rightarrow$ EtOAc:MeOH (90:10).

tert-Butyl (S)-2-((4-methyl-2-oxo-2H-chromen-7-yl)carbamoyl)pyrrolidine-1-carboxylate (9)

tert-Butyl (S)-2-((4-methyl-2-oxo-2H-chromen-7-yl)carbamoyl)pyrrolidine-1-carboxylate was prepared according to general procedure A using 7 and 7-amino-methylcoumarine and was obtained as a white crystalline solid. The product was used without further purification.

Yield: $89 \%$

${ }^{1} \mathrm{H}-\mathrm{NMR}:\left(400 \mathrm{MHz}\right.$, Acetone- $\left.d_{6}\right) \delta 9.89(\mathrm{~s}, 1 \mathrm{H}), 7.81(\mathrm{~d}, J=20.2 \mathrm{~Hz}, 1 \mathrm{H}), 7.64(\mathrm{~d}, J=11.2 \mathrm{~Hz}, 1 \mathrm{H}), 7.42(\mathrm{~m}, 1 \mathrm{H}), 6.14$ (s, 1H), $4.36(\mathrm{~m}, 1 \mathrm{H}), 3.43(\mathrm{dt}, J=17.1,10.2,7.3 \mathrm{~Hz}, 2 \mathrm{H}), 3.11(\mathrm{q}, J=7.3 \mathrm{~Hz}, 2 \mathrm{H}), 2.40(\mathrm{~s}, 3 \mathrm{H}), 2.01(\mathrm{~m}, 2 \mathrm{H}), 1.43(\mathrm{~s}$, $9 \mathrm{H})$.

${ }^{13}$ C-NMR: (101 MHz, Acetone) $\delta$ 173.21, 160.93, 154.91, 153.31, 143.23, 126.33, 116.20, 113.54, 107.47, 79.69, $61.69,46.39,30.59,28.53,18.39,8.83$.

ESI-MS': m/z: $373.4[\mathrm{M}+\mathrm{H}]^{+} ; 395.4[\mathrm{M}+\mathrm{Na}]^{+} ; 767.4[2 \mathrm{M}+\mathrm{Na}]^{+}$

ESI-MS: $\mathbf{m} / \mathbf{z :} 371.3[\mathrm{M}-\mathrm{H}]^{-}$

(S)-tert-Butyl 4,4-difluoro-2-((4-methyl-2-oxo-2H-chromen-7-yl)carbamoyl)pyrrolidine-1-carboxylate (10)

(S)-tert-Butyl 4,4-difluoro-2-((4-methyl-2-oxo-2H-chromen-7-yl)carbamoyl)pyrrolidine-1-carboxylate was prepared from 8 and 7-amino-4-methylcoumarine following general procedure A. The title compound was obtained as an offwhite crystalline solid. The crude product was used without further purification.

Yield: $100 \%$

${ }^{1} \mathrm{H}$ NMR $\left(400 \mathrm{MHz}, \mathrm{CDCl}_{3}\right) \delta 7.82(\mathrm{~d}, J=9.60 \mathrm{~Hz}, 1 \mathrm{H}), 7.67(\mathrm{~s}, 1 \mathrm{H}), 7.44(\mathrm{~m}, 1 \mathrm{H}), 6.08-6.15(\mathrm{~m}, 1 \mathrm{H}), 4.75(\mathrm{t}, J=7.69$ $\mathrm{Hz}, 1 \mathrm{H}), 3.66(\mathrm{~m}, 2 \mathrm{H}), 2.80(\mathrm{~m}, 2 \mathrm{H}), 2.37(\mathrm{~s}, 3 \mathrm{H}), 1.43(\mathrm{~s}, 9 \mathrm{H})$.

ESI-MS': m/z: $409.39[\mathrm{M}+\mathrm{H}]^{+} ; 431,4[\mathrm{M}+\mathrm{Na}]^{+}$;

ESI-MS: $\mathrm{m} / \mathrm{z}:$ 407,4 [M-H]

\section{(S)-tert-Butyl 2-((4-nitrophenyl)carbamoyl)pyrrolidine-1-carboxylate (11)}

(S)-tert-Butyl 2-((4-nitrophenyl)carbamoyl)pyrrolidine-1-carboxylate was prepared from 7 and para-nitroaniline using general procedure $A$. The title compound was obtained as a beige crystalline solid and was used without further purification. 
Yield: $98 \%$

${ }^{1} \mathrm{H}$ NMR (400 MHz, Acetone- $\left.\boldsymbol{d}_{6}\right) \boldsymbol{\delta} 9.99(\mathrm{~m}, 1 \mathrm{H}), 8.09(\mathrm{~m}, 2 \mathrm{H}), 7.82(\mathrm{~m}, 2 \mathrm{H}), 4.25(\mathrm{~m}, 1 \mathrm{H}), 3.31(\mathrm{~m}, 2 \mathrm{H}), 3.10(\mathrm{q}, J=7.3$ $\mathrm{Hz}, 2 \mathrm{H}), 1.93(\mathrm{dt}, J=4.4,2.2 \mathrm{~Hz}, 2 \mathrm{H}), 1.21(\mathrm{~s}, 9 \mathrm{H})$.

${ }^{13}$ C NMR (101 MHz, Acetone) $\delta$ 174.69, 154.16, 146.01, 143.85, 125.54, 119.81, 80.06, 62.27, 46.80, 25.21, 19.84, 9.21.

ESI-MS $:$ m/z: $236.2[\mathrm{M}-\mathrm{Boc}+\mathrm{H}]^{+}$

ESI-MS': m/z: $334.1\left[\mathrm{M}-\mathrm{H}^{-}\right.$

(S)-tert-Butyl 4,4-difluoro-2-((4-nitrophenyl)carbamoyl)pyrrolidine-1-carboxylate (12)

(S)-tert-Butyl 4,4-difluoro-2-((4-nitrophenyl)carbamoyl)pyrrolidine-1-carboxylate was prepared according to general procedure A using $\mathbf{8}$ and para-nitroaniline and was obtained as an amorphous yellow solid. The crude product was used without further purification.

Yield: $97 \%$

${ }^{1} \mathrm{H}$ NMR $\left(400 \mathrm{MHz}, \mathrm{CDCl}_{3}\right) \delta 9.93(\mathrm{~s}, 1 \mathrm{H}), 8.17(\mathrm{~d}, J=8.4 \mathrm{~Hz}, 2 \mathrm{H}) 7.68(\mathrm{~m}, 2 \mathrm{H}), 4.59(\mathrm{dd}, J=8.4,5.9 \mathrm{~Hz}, 1 \mathrm{H}), 3.92(\mathrm{~m}$, $2 \mathrm{H}), 2.69(\mathrm{~m}, 2 \mathrm{H}), 1.48(\mathrm{~s}, 9 \mathrm{H})$.

ESI-MS $:$ m/z: $272.1[\mathrm{M}-\mathrm{Boc}+\mathrm{H}]^{+}$

ESI-MS: m/z: $370.1[\mathrm{M}-\mathrm{H}]^{-}$

(S)-tert-Butyl 2-((4-hydroxynaphthalen-1-yl)carbamoyl)pyrrolidine-1-carboxylate (13)

(S)-tert-Butyl 2-((4-hydroxynaphthalen-1-yl)carbamoyl)pyrrolidine-1-carboxylate was prepared from 7 and 4 aminonaphthol hydrochloride using general procedure B. The crude product was further purified using NP-flash chromatography: heptane:EtOAc $(75: 25) \rightarrow$ heptane:EtOAc $(30: 70)$ yielding the title compound as a beige foam like structure.

Yield: $89 \%$

${ }^{1} \mathrm{H}$ NMR $\left(400 \mathrm{MHz}, \mathrm{CDCl}_{3}\right) \delta 8.99(\mathrm{~s}, 1 \mathrm{H}), 7.91(\mathrm{~d}, J=8.2 \mathrm{~Hz}, 1 \mathrm{H}), 7.65(\mathrm{~m}, 1 \mathrm{H}), 7.30(\mathrm{t}, J=7.1 \mathrm{~Hz}, 1 \mathrm{H}), 7.23(\mathrm{~m}, 1 \mathrm{H})$, $6.96(\mathrm{~m}, 1 \mathrm{H}), 6.30(\mathrm{~d}, J=8.0 \mathrm{~Hz}, 1 \mathrm{H}), 4.41(\mathrm{~m}, 1 \mathrm{H}), 3.99(\mathrm{q}, J=7.1 \mathrm{~Hz}, 1 \mathrm{H}), 3.43(\mathrm{~m}, 2 \mathrm{H}), 2.26(\mathrm{~m}, 1 \mathrm{H}), 1.68(\mathrm{~m}, 2 \mathrm{H})$, $1.42(\mathrm{~s}, 1 \mathrm{H})$.

${ }^{13} \mathrm{C}$ NMR (101 MHz, $\left.\mathrm{CDCl}_{3}\right) \delta$ 171.60, 151.19, 135.03, 126.64, 125.35, 124.91, 122.86, 121.37, 108.56, 81.22, 60.59, 47.52, 28.61, 21.1614 .31$. 


\section{(S)-tert-Butyl 4,4-difluoro-2-((4-hydroxynaphthalen-1-yl)carbamoyl)pyrrolidine-1-carboxylate (14)}

(S)-tert-Butyl 4,4-difluoro-2-((4-hydroxynaphthalen-1-yl)carbamoyl)pyrrolidine-1-carboxylate was prepared from 8 and 4-amino-naphthol hydrochloride; using general procedure B. The crude product was further purified using RPflash chromatography: water: $\mathrm{MeCN}(75: 25) \rightarrow 100 \% \mathrm{MeCN}$; yielding the title compound as a beige crystalline solid.

Yield: $32 \%$

${ }^{1} \mathrm{H}$ NMR (400 MHz, $\left.\mathrm{CDCl}_{3}\right) \delta 8.87(\mathrm{~s}, 1 \mathrm{H}), 7.94(\mathrm{~m}, 1 \mathrm{H}), 7.73(\mathrm{~s}, 1 \mathrm{H}), 7.38$ (ddd, $J=8.3,6.7,1.4 \mathrm{~Hz}, 1 \mathrm{H}$ ), 7.30 (ddd, $J=$ 8.1, 6.8, 1.2 Hz, 1H), $7.23(\mathrm{~d}, J=9.1 \mathrm{~Hz}, 1 \mathrm{H}), 6.32(\mathrm{~d}, J=8.0 \mathrm{~Hz}, 1 \mathrm{H}), 4.76-4.81(\mathrm{~m}, 1 \mathrm{H}), 3.89(\mathrm{t}, J=12.3 \mathrm{~Hz}, 1 \mathrm{H}), 3.73$ $(\mathrm{m}, 1 \mathrm{H}), 3.08(\mathrm{~s}, 1 \mathrm{H}), 2.62(\mathrm{~s}, 1 \mathrm{H}), 1.48(\mathrm{~s}, 9 \mathrm{H})$.

${ }^{13} \mathrm{C}$ NMR $\left(101 \mathrm{MHz}, \mathrm{CDCl}_{3}\right)$ 8 169.64, 155.67, 126.77, 125.11, 125.01, 122.66, 121.16, 108.40, 82.69, 58.58, $53.62(\mathrm{t}$, $J=31.3 \mathrm{~Hz}), 34.48,28.33$.

ESI-MS': m/z: $293[\mathrm{M}-\mathrm{Boc}+\mathrm{H}]^{+} ; 415[\mathrm{M}+\mathrm{Na}]^{+} ; 786[2 \mathrm{M}+\mathrm{H}]^{+}$

ESI-MS: $\mathbf{m} / \mathbf{z}: 391[\mathrm{M}-\mathrm{H}]^{-}$

(S)-N-(4-Methyl-2-oxo-2H-chromen-7-yl)pyrrolidine-2-carboxamide hydrochloride (15)

(S)-N-(4-Methyl-2-oxo-2H-chromen-7-yl)pyrrolidine-2-carboxamide hydrochloride was prepared from 9 using general procedure $C$ and was obtained as a beige crystalline solid. The product was used without further purification.

Yield: $100 \%$

${ }^{1} \mathrm{H}$ NMR (400 MHz, DMSO-d 6 ) $\delta 10.85(\mathrm{~s}, 1 \mathrm{H}), 9.36(\mathrm{dd}, \mathrm{J}=10.2,5.0 \mathrm{~Hz}, 1 \mathrm{H}), 7.04(\mathrm{~d}, \mathrm{~J}=1.9 \mathrm{~Hz}, 1 \mathrm{H}), 6.98(\mathrm{~d}, \mathrm{~J}=8.7$ $\mathrm{Hz}, 1 \mathrm{H}), 6.81(\mathrm{dd}, \mathrm{J}=8.7,1.9 \mathrm{~Hz}, 1 \mathrm{H}), 5.52(\mathrm{~s}, 1 \mathrm{H}), 3.70(\mathrm{dd}, \mathrm{J}=12.7,6.1 \mathrm{~Hz}, 1 \mathrm{H}), 1.75-1.72(\mathrm{~m}, 2 \mathrm{H}), 1.71-1.66(\mathrm{~m}$, $1 \mathrm{H}), 1.63(\mathrm{~s}, 3 \mathrm{H}), 1.24(\mathrm{dd}, \mathrm{J}=15.0,7.7 \mathrm{~Hz}, 1 \mathrm{H}), 1.20-1.13(\mathrm{~m}, 2 \mathrm{H})$.

${ }^{13}$ C NMR (101 MHz, DMSO) $\delta$ 167.68, 159.98, 153.55, 153.14, 141.55, 126.15, 115.68, 115.51, 112.74, 106.12, 59.77, $45.77,29.76,23.67,18.08$.

ESI-MS': m/z: $273.1[\mathrm{M}+\mathrm{H}]^{+} ; 295.2[\mathrm{M}+\mathrm{Na}]^{+} ; 545.3[2 \mathrm{M}+\mathrm{H}]^{+} ; 567.3[2 \mathrm{M}+\mathrm{Na}]^{+}$

ESI-MS: $\mathbf{m} / \mathbf{z :} 271.2[\mathrm{M}-\mathrm{H}]^{-}$

(S)-4,4-Difluoro- $\mathrm{N}$-(4-methyl-2-oxo-2H-chromen-7-yl)pyrrolidine-2-carboxamide hydrochloride (16)

(S)-4,4-Difluoro- $\mathrm{N}$-(4-methyl-2-oxo-2H-chromen-7-yl)pyrrolidine-2-carboxamide hydrochloride was prepared from 10 following general procedure $C$ and was obtained as an off-white crystalline solid. The product was used without further purification.

Yield: $94 \%$ 
${ }^{1} \mathrm{H}$ NMR $\left(400 \mathrm{MHz}, \mathrm{CDCl}_{3}\right) \delta 7.89(\mathrm{~d}, J=2.11 \mathrm{~Hz}, 1 \mathrm{H}), 7.79(\mathrm{~d}, J=8.67 \mathrm{~Hz}, 1 \mathrm{H}), 7.54(\mathrm{dd}, J=2.13,8.65 \mathrm{~Hz}, 1 \mathrm{H}), 6.30(\mathrm{~s}$, $1 \mathrm{H}), 4.81(\mathrm{~m}, 1 \mathrm{H}), 3.75(\mathrm{~m}, 2 \mathrm{H}), 2.83(\mathrm{~m}, 2 \mathrm{H}), 2.49(\mathrm{~s}, 3 \mathrm{H})$.

${ }^{13}$ C NMR (101 MHz, $\left.\mathrm{CDCl}_{3}\right) \delta$ 174.82, 168.73, 151.20, 149.61, 143.88, 131.91, 130.86, 129.49, 127.24, 54.31, 50.37, $38.20,19.50$.

ESI-MS : m/z: $309.1[\mathrm{M}+\mathrm{H}]^{+} ; 331.1[\mathrm{M}+\mathrm{Na}]^{+}$

ESI-MS: $\mathbf{m} / \mathbf{z}: 308.2[\mathrm{M}-\mathrm{H}]^{-}$

(S)-N-(4-nitrophenyl)pyrrolidine-2-carboxamide hydrochloride (17)

(S)-N-(4-nitrophenyl)pyrrolidine-2-carboxamide hydrochloride was prepared from $\mathbf{1 1}$ following general procedure $\mathrm{C}$ and was obtained as a yellow crystalline solid. The product was used without further purification.

Yield: $100 \%$

${ }^{1} \mathrm{H}$ NMR (400 MHz, DMSO-d $) \delta 11.87(\mathrm{~s}, 1 \mathrm{H}), 8.27-8.17(\mathrm{~m}, 2 \mathrm{H}), 7.96-7.88(\mathrm{~m}, 2 \mathrm{H}), 4.53(\mathrm{dd}, J=8.4,6.7 \mathrm{~Hz}, 1 \mathrm{H})$, $3.35-3.22(\mathrm{~m}, 2 \mathrm{H}), 2.54-2.42(\mathrm{~m}, 1 \mathrm{H}), 2.01(\mathrm{dt}, J=8.2,6.6 \mathrm{~Hz}, 1 \mathrm{H}), 1.97-1.87(\mathrm{~m}, 2 \mathrm{H})$.

${ }^{13}$ C NMR (101 MHz, DMSO) $\delta$ 167.91, 144.47, 142.76, 125.02, 119.34, 59.78, 45.76, 29.74, 23.60 (9).

ESI-MS': m/z: $236.1[\mathrm{M}+\mathrm{H}]^{+}$

ESI-MS: m/z: $234.2[\mathrm{M}-\mathrm{H}]^{-}$

(S)-4,4-Difluoro-N-(4-nitrophenyl)pyrrolidine-2-carboxamide hydrochloride (18)

(S)-4,4-difluoro- $N$-(4-nitrophenyl)pyrrolidine-2-carboxamide hydrochloride was prepared from 12 following general procedure $\mathrm{C}$ and was obtained as yellow crystalline solid. The product was used without further purification.

Yield: $97 \%$

${ }^{1} \mathrm{H}$ NMR (400 MHz, DMSO-d $\left.\boldsymbol{d}_{6}\right) 11.92(\mathrm{~s}, 1 \mathrm{H}), 10.36(\mathrm{~s}, 1 \mathrm{H}), 8.29(\mathrm{~m}, 2 \mathrm{H}), 7.94(\mathrm{~m}, 2 \mathrm{H}), 4.87(\mathrm{t}, \mathrm{J}=8.5 \mathrm{~Hz}, 1 \mathrm{H}), 3.82$ $(\mathrm{t}, J=12.3 \mathrm{~Hz}, 2 \mathrm{H}), 3.16$ (tdd, $J=14.4,11.1,8.5 \mathrm{~Hz}, 1 \mathrm{H}), 2.78(\mathrm{~m}, 1 \mathrm{H})$.

${ }^{13}$ C NMR (101 MHz, DMSO) $\delta$ 166.03, 144.55, 143.43, 127.78-130.25 (t, $\left.J=244.2 \mathrm{~Hz}\right), 125.52,125.31,119.93,58.59$, $51.13(\mathrm{t}, J=33.7 \mathrm{~Hz}), 38.03(\mathrm{t}, J=25.6 \mathrm{~Hz})$.

ESI-MS : m/z: $272.1[\mathrm{M}+\mathrm{H}]^{+}$

ESI-MS: m/z: $271.2[\mathrm{M}-\mathrm{H}]^{-}$

(S)-N-(4-Hydroxynaphthalen-1-yl)pyrrolidine-2-carboxamide hydrochloride (19) 
(S)-N-(4-hydroxynaphthalen-1-yl)pyrrolidine-2-carboxamide hydrochloride was prepared from 13 using general method $\mathrm{D}$. The crude was converted into an $\mathrm{HCl}$ salt by addition of a $1 \mathrm{M} \mathrm{HCl}$ solution in diethyl ether $(2$ molar equivalents added to a solution of the crude product in methanol). The formed precipitate was washed with diethylether and dried in vacuo, yielding the title compound as a beige crystalline solid. The product was used without further purification.

Yield: $97 \%$

${ }^{1} \mathrm{H}$ NMR (400 MHz, DMSO- $\left.d_{6}\right) \delta 10.52(\mathrm{~s}, 1 \mathrm{H}), 10.41(\mathrm{~s}, 1 \mathrm{H}), 8.67(\mathrm{~s}, 1 \mathrm{H}), 8.13-8.21(\mathrm{~m}, 1 \mathrm{H}), 7.86-7.94(\mathrm{~m}, 1 \mathrm{H})$, 7.54 (ddd, $J=8.5,6.8,1.5 \mathrm{~Hz}, 1 \mathrm{H}$ ), 7.48 (ddd, $J=8.1,6.8,1.3 \mathrm{~Hz}, 1 \mathrm{H}$ ), $7.34(\mathrm{~d}, J=8.0 \mathrm{~Hz}, 1 \mathrm{H}), 6.92(\mathrm{~d}, J=8.1 \mathrm{~Hz}, 1 \mathrm{H}$ ), $4.57(\mathrm{t}, J=7.8 \mathrm{~Hz}, 1 \mathrm{H}), 3.22-3.31(\mathrm{~m}, 2 \mathrm{H}), 2.52-2.59(\mathrm{~m}, 1 \mathrm{H}), 2.10(\mathrm{dq}, J=12.5,7.4 \mathrm{~Hz}, 1 \mathrm{H}), 1.93-2.03(\mathrm{~m}, 2 \mathrm{H})$.

${ }^{13}$ C NMR (101 MHz, DMSO) $\delta$ 167.91, 152.04, 129.69, 126.40, 124.85, 124.77, 123.94, 123.29, 122.68, 122.42, $107.31,59.29,45.63,38.89,30.07$.

ESI-MS $:$ m/z: $257.2[\mathrm{M}+\mathrm{H}]^{+} ; 279.40[\mathrm{M}+\mathrm{Na}]^{+}$

(S)-4,4-Difluoro-N-(4-hydroxynaphthalen-1-yl)pyrrolidine-2-carboxamide hydrochloride (20)

(S)-4,4-Difluoro- $N$-(4-hydroxynaphthalen-1-yl)pyrrolidine-2-carboxamide hydrochloride title was prepared from 14 following general procedure $\mathrm{D}$. The crude was converted into an $\mathrm{HCl}$ salt by addition of a $1 \mathrm{M} \mathrm{HCl}$ solution in diethyl ether ( 2 molar equivalents added to a solution of the crude product in methanol). The formed precipitate was washed with diethylether and dried in vacuo, yielding the title compound as a beige crystalline solid.

Yield: $98 \%$

${ }^{1} \mathrm{H}$ NMR $\left(400 \mathrm{MHz}, \mathrm{DMSO}-d_{6}\right) \delta 10.64(\mathrm{~s}, 1 \mathrm{H}), 10.44(\mathrm{~s}, 1 \mathrm{H}), 8.17(\mathrm{~d}, J=8.0 \mathrm{~Hz}, 1 \mathrm{H}), 7.94(\mathrm{~d}, J=8.1 \mathrm{~Hz}, 1 \mathrm{H}), 7.52(\mathrm{~m}$, $2 \mathrm{H}), 7.36(\mathrm{~d}, J=8.0 \mathrm{~Hz}, 1 \mathrm{H}), 6.93(\mathrm{~d}, J=8.0 \mathrm{~Hz}, 1 \mathrm{H}), 4.93(\mathrm{t}, J=8.4 \mathrm{~Hz}, 1 \mathrm{H}), 3.81(\mathrm{t}, J=12.4 \mathrm{~Hz}, 2 \mathrm{H}), 3.11-3.28(\mathrm{~m}$, $1 \mathrm{H}), 2.82(\mathrm{qd}, J=14.5,8.3 \mathrm{~Hz}, 1 \mathrm{H})$.

${ }^{13}$ C NMR (101 MHz, DMSO) $\delta$ 166.22, 152.56, 130.01, 126.86, 125.33, 125.19, 124.26, 123.51, 123.19, 122.83, $107.72,58.19,51.11(\mathrm{t}, J=24.95 \mathrm{~Hz}), 38.42(\mathrm{t}, J=33.79 \mathrm{~Hz})$.

ESI-MS': m/z: $293.3[\mathrm{M}+\mathrm{H}]^{+} ; 315.0[\mathrm{M}+\mathrm{Na}]^{+}$

tert-Butyl ((R)-1-((S)-2-((4-methyl-2-oxo-2H-chromen-7-yl)carbamoyl)pyrrolidin-1-yl)-1-oxopropan-2yl)carbamate (23)

tert-Butyl ((R)-1-((S)-2-((4-methyl-2-oxo-2H-chromen-7-yl)carbamoyl)pyrrolidin-1-yl)-1-oxopropan-2-yl)carbamate was prepared from Boc-D-ala-OH (1.1eq.) and $\mathbf{1 5}$ following general procedure $\mathrm{E}$, yielding the title compound as a white amorphous solid. The product was used without further purification. 
Yield: $69.3 \%$

${ }^{1} \mathrm{H}$ NMR (400 MHz, DMSO-d $\left.\mathrm{d}_{6}\right) \delta 10.16(\mathrm{~s}, 1 \mathrm{H}), 7.74(\mathrm{~m}, 1 \mathrm{H}), 7.72(\mathrm{~d}, J=2.9 \mathrm{~Hz}, 1 \mathrm{H}), 7.52(\mathrm{ddd}, J=8.7,4.7,2.0 \mathrm{~Hz}, 1 \mathrm{H})$, $7.00(\mathrm{~d}, J=7.4 \mathrm{~Hz}, 1 \mathrm{H}), 6.27(\mathrm{~m}, 1 \mathrm{H}), 4.42(\mathrm{dd}, J=8.3,3.3 \mathrm{~Hz}, 1 \mathrm{H}), 4.31(\mathrm{q}, J=7.1 \mathrm{~Hz}, 1 \mathrm{H}), 3.71(\mathrm{td}, J=9.4,7.7,4.5 \mathrm{~Hz}$, $1 \mathrm{H}), 3.56(\mathrm{dt}, J=10.0,6.8 \mathrm{~Hz}, 1 \mathrm{H}), 3.45(\mathrm{t}, J=6.9 \mathrm{~Hz}, 1 \mathrm{H}), 2.39(\mathrm{~d}, J=1.2 \mathrm{~Hz}, 3 \mathrm{H}), 2.12-2.18(\mathrm{~m}, 1 \mathrm{H}), 1.86(\mathrm{~m}, 2 \mathrm{H})$, $1.36(2 \times s, 9 H), 1.16(d d, J=13.4,6.3 \mathrm{~Hz}, 2 \mathrm{H})$. Rotamers

${ }^{13}$ C NMR (101 MHz, DMSO) $\delta$ 171.25, 171.12, 160.05, 155.01, 153.64, 153.13, 142.19, 125.87, 115.30, 115.08, $112.34,105.77,78.23,60.68,59.79,47.73,46.76,28.20,24.51,18.02,17.17$.

ESI-MS ${ }^{+}: \mathrm{m} / \mathrm{z}: 343.2[\mathrm{M}-\mathrm{Boc}+\mathrm{H}]^{+} ; 466.2[\mathrm{M}+\mathrm{Na}]^{+} ; 905.4[2 \mathrm{M}+\mathrm{Na}]^{+}$

ESI-MS: $\mathrm{m} / \mathrm{z}: 442.2[\mathrm{M}-\mathrm{H}]^{-}$

tert-Butyl ((R)-1-((S)-4,4-difluoro-2-((4-methyl-2-oxo-2H-chromen-7-yl)carbamoyl)pyrrolidin-1-yl)-1-oxopropan-2yl)carbamate (24)

tert-Butyl ((R)-1-((S)-4,4-difluoro-2-((4-methyl-2-oxo-2H-chromen-7-yl)carbamoyl)pyrrolidin-1-yl)-1-oxopropan-2$\mathrm{yl)carbamate}$ was prepared from Boc-D-Ala-OH and $\mathbf{1 6}$ following general procedure $\mathrm{E}$ and was obtained as an offwhite crystalline solid. The product was used without further purification.

Yield: $73.6 \%$

${ }^{1} \mathrm{H}$ NMR $\left(400 \mathrm{MHz} \mathrm{CDCl}_{3}\right) \delta 9.30(\mathrm{~s}, 1 \mathrm{H}), 1.41(\mathrm{~s}, 9 \mathrm{H}), 7.71(\mathrm{~m}, 1 \mathrm{H}), 7.65(\mathrm{~m}, 1 \mathrm{H}), 7.48(\mathrm{~d}, J=8.68 \mathrm{~Hz}, 1 \mathrm{H}), 6.19(\mathrm{~d}, J=$ $1.52 \mathrm{~Hz}, 1 \mathrm{H}), 5.23(\mathrm{~d}, J=6.45 \mathrm{~Hz}, 1 \mathrm{H}), 5.03(\mathrm{dd}, J=4.35,9.59 \mathrm{~Hz}, 1 \mathrm{H}), 4.29(\mathrm{q}, J=6.81 \mathrm{~Hz}, 1 \mathrm{H}), 4.14(\mathrm{~m}, 1 \mathrm{H}), 3.99(\mathrm{~m}$, $1 \mathrm{H}), 3.01(\mathrm{~m}, 1 \mathrm{H}), 2.72(\mathrm{~m}, 1 \mathrm{H}), 2.41(\mathrm{~s}, 3 \mathrm{H}), 1.50(\mathrm{~m}, 3 \mathrm{H})$.

${ }^{13} \mathrm{C}$ NMR (101 MHz, CDCl $)$ ) 173.07, 167.72, 161.03, 155.79, 153.99, 152.16, 141.06, 126.15, 124.83, 116.73, 116.31, $113.57,108.04,80.80,58.79,53.74,53.43,48.49,28.26,18.56,16.76$.

ESI-MS ${ }^{+}: \mathrm{m} / \mathrm{z}: 380.2[\mathrm{M}-\mathrm{Boc}+\mathrm{H}]^{+} ; 502.5[\mathrm{M}+\mathrm{Na}]^{+} ; 981.4[2 \mathrm{M}+\mathrm{Na}]^{+}$

ESI-MS: $\mathrm{m} / \mathrm{z}:$ 378.3) [M-H]

(S)-tert-Butyl (2-(2-((4-nitrophenyl)carbamoyl)pyrrolidin-1-yl)-2-oxoethyl)carbamate (25)

(S)-tert-Butyl (2-(2-((4-nitrophenyl)carbamoyl)pyrrolidin-1-yl)-2-oxoethyl)carbamate was prepared from N-alpha-tBoc-glycine and $\mathbf{1 7}$ following general procedure $\mathrm{E}$, yielding the title compound as a white crystalline solid. The crude product was used without further purification.

Yield: $52.6 \%$ 
${ }^{1} \mathrm{H}$ NMR (400 MHz, CDCl $) \delta 9.95(\mathrm{~s}, 1 \mathrm{H}), 8.20(\mathrm{~m}, 2 \mathrm{H}), 7.72(\mathrm{~m}, 2 \mathrm{H}), 5.36(\mathrm{~s}, 1 \mathrm{H}), 4.84(\mathrm{~m}, 1 \mathrm{H}), 3.99(\mathrm{~d}, J=16.62 \mathrm{~Hz}$, $2 \mathrm{H}), 3.62(\mathrm{~m}, 1 \mathrm{H}), 3.47(\mathrm{td}, J=7.23,9.75 \mathrm{~Hz}, 1 \mathrm{H}), 3.13(\mathrm{qd}, J=4.81,7.34 \mathrm{~Hz}, 1 \mathrm{H}), 2.64(\mathrm{dd}, J=6.00,12.96 \mathrm{~Hz}, 1 \mathrm{H})$, $2.15(\mathrm{ddd}, J=3.19,7.34,10.69 \mathrm{~Hz}, 1 \mathrm{H}), 1.93(\mathrm{~m}, 1 \mathrm{H}), 1.49(\mathrm{~s}, 9 \mathrm{H})$.

ESI-MS $:$ m/z: $293.1[\mathrm{M}-\mathrm{Boc}+\mathrm{H}]^{+} ; 415[\mathrm{M}+\mathrm{Na}]^{+}$

ESI-MS: $\mathbf{m} / \mathbf{z}: 391.4[\mathrm{M}-\mathrm{H}]^{-}$

(S)-tert-Butyl (2-(4,4-difluoro-2-((4-nitrophenyl)carbamoyl)pyrrolidin-1-yl)-2-oxoethyl)carbamate (26)

(S)-tert-butyl (2-(4,4-difluoro-2-((4-nitrophenyl)carbamoyl)pyrrolidin-1-yl)-2-oxoethyl)carbamate was prepared from $\mathrm{N}$-alpha-t-Boc-glycine and $\mathbf{1 8}$ general procedure $\mathrm{E}$ and was obtained as a yellow crystalline solid. The product was used without further purification.

Yield: $90 \%$

${ }^{1} \mathrm{H}$ NMR (400 MHz, DMSO-d d $\delta 10.76(\mathrm{~s}, 1 \mathrm{H}), 8.25(\mathrm{~d}, J=9.3 \mathrm{~Hz}, 2 \mathrm{H}), 7.84(\mathrm{~d}, J=9.1 \mathrm{~Hz}, 2 \mathrm{H}), 7.01(\mathrm{t}, J=6.1 \mathrm{~Hz}, 2 \mathrm{H})$, $4.69(\mathrm{dd}, J=9.2,5.6 \mathrm{~Hz}, 1 \mathrm{H}), 4.12(\mathrm{~m}, 2 \mathrm{H}), 3.91(\mathrm{dd}, J=17.4,6.5 \mathrm{~Hz}, 1 \mathrm{H}), 3.71(\mathrm{~m}, 1 \mathrm{H}), 3.37(\mathrm{~d}, J=3.2 \mathrm{~Hz}, 4 \mathrm{H}), 1.37$ $(\mathrm{s}, 9 \mathrm{H})$.

${ }^{13}$ C NMR (101 MHz, DMSO) $\delta$ 169.60, 168.86, 156.30, 145.29, 142.88, 125.47, 119.98, 142.88, 125.47, 119.98, $119.51,78.45,58.76,52.83(t, J=31,3 \mathrm{~Hz}), 42.72,37.20,28.63$.

ESI-MS $:$ m/z: $329.2[\mathrm{M}-\mathrm{Boc}+\mathrm{H}]^{+} ; 429.2[\mathrm{M}+\mathrm{H}]^{+} ; 441.2[\mathrm{M}+\mathrm{Na}]^{+}$

ESI-MS: $\mathrm{m} / \mathrm{z}:$ 427,2 [M-H]

tert-Butyl ((R)-1-((S)-2-((4-nitrophenyl)carbamoyl)pyrrolidin-1-yl)-1-oxopropan-2-yl)carbamate (27)

tert-Butyl ((R)-1-((S)-2-((4-nitrophenyl)carbamoyl)pyrrolidin-1-yl)-1-oxopropan-2-yl)carbamate was prepared from Boc-D-ala-OH and 17 following general procedure $E$ and was obtained as a yellow sticky oil. The crude product was used without further purification.

Yield: $73.5 \%$

${ }^{1} \mathrm{H}$ NMR $\left(400 \mathrm{MHz}, \mathrm{CDCl}_{3}\right) \delta 9.60(\mathrm{~s}, 1 \mathrm{H}), 8.18(\mathrm{~m}, 2 \mathrm{H}), 7.84(\mathrm{~d}, J=8.77 \mathrm{~Hz}, 2 \mathrm{H}), 5.15(\mathrm{~s}, 1 \mathrm{H}), 4.83(\mathrm{dd}, J=1.83,7.97$ $\mathrm{Hz}, 1 \mathrm{H}), 4.41(\mathrm{~m}, 1 \mathrm{H}), 3.94(\mathrm{~m}, 1 \mathrm{H}), 3.54(\mathrm{q}, J=8.74 \mathrm{~Hz}, 1 \mathrm{H}), 2.59(\mathrm{~m}, 1 \mathrm{H}), 2.11(\mathrm{dd}, J=2.99,4.60 \mathrm{~Hz}, 1 \mathrm{H}), 2.07(\mathrm{~s}, 3 \mathrm{H})$, $1.47(\mathrm{~m}, 2 \mathrm{H}), 1.40(\mathrm{~s}, 9 \mathrm{H})$.

ESI-MS': m/z: $307.1[\mathrm{M}-\mathrm{Boc}+\mathrm{H}]^{+} ; 429.1[\mathrm{M}+\mathrm{Na}]^{+}$

ESI-MS: : m/z: $405.3[\mathrm{M}-\mathrm{H}]^{-}$

Purity: $94 \%$ 
tert-Butyl ((R)-1-((S)-4,4-difluoro-2-((4-nitrophenyl)carbamoyl)pyrrolidin-1-yl)-1-oxopropan-2-yl)carbamate (28)

tert-Butyl ((R)-1-((S)-4,4-difluoro-2-((4-nitrophenyl)carbamoyl)pyrrolidin-1-yl)-1-oxopropan-2-yl)carbamate was prepared from Boc-D-ala-OH and $\mathbf{1 8}$ following general procedure E and was obtained a s a yellow crystalline solid. The product was used without further purification.

Yield: $98 \%$

${ }^{1} \mathrm{H}$ NMR (400 MHz, DMSO-d $) \delta 10.43(\mathrm{~s}, 1 \mathrm{H}), 8.24$ (d, J = 9.2 Hz, 2H), 7.86 (dd, J = 9.2, 1.9 Hz, 2), 7.26 (d, J = $7.4 \mathrm{~Hz}$, $1 \mathrm{H}), 4.71(\mathrm{dd}, J=9.3,5.2 \mathrm{~Hz}, 1 \mathrm{H}), 4.26(\mathrm{dt}, J=15.3,7.6 \mathrm{~Hz}, 1 \mathrm{H}), 4.15(\mathrm{q}, J=13.2,12.7 \mathrm{~Hz}, 1 \mathrm{H}), 3.77(\mathrm{~m}, 1 \mathrm{H}), 2.85(\mathrm{~m}$, 1H), $2.59(\mathrm{dt}, J=14.0,6.8 \mathrm{~Hz}, 1 \mathrm{H}), 1.37(\mathrm{~s}, 9 \mathrm{H}), 1.18(\mathrm{~m}, 3 \mathrm{H})$.

${ }^{13}$ C NMR (101 MHz, DMSO) $\delta$ 172.10, 169.60, 155.61, 145.09, 142.96, 125.41, 119.64, 106.85, 78.90, 60.24, 58.85, $48.08,36.98,28.59,21.20$.

ESI-MS ${ }^{+}: \mathbf{m} / \mathbf{z :} 465.2[\mathrm{M}+\mathrm{Na}]^{+}$

ESI-MS: m/z: $441.2[\mathrm{M}-\mathrm{H}]^{-}$

(S)-tert-Butyl (2-(2-((4-hydroxynaphthalen-1-yl)carbamoyl)pyrrolidin-1-yl)-2-oxoethyl)carbamate (29)

(S)-tert-Butyl (2-(2-((4-hydroxynaphthalen-1-yl)carbamoyl)pyrrolidin-1-yl)-2-oxoethyl)carbamate was prepared from $\mathrm{N}$-alpha-t-Boc-Glycine and $\mathbf{1 9}$ following general procedure $\mathrm{E}$ and was obtained as an off-white crystalline solid The product was used without further purification.

Yield: $84 \%$

${ }^{1} \mathrm{H}$ NMR $\left(400 \mathrm{MHz}\right.$, DMSO- $\left.\boldsymbol{d}_{6}\right) \boldsymbol{\delta} 9.61(\mathrm{~s}, 1 \mathrm{H}), 8.15(\mathrm{~m}, 1 \mathrm{H}), 7.87(\mathrm{~m}, 1 \mathrm{H}), 7.53(\mathrm{~m}, 1 \mathrm{H}), 7.46(\mathrm{~m}, 1 \mathrm{H}), 7.22(\mathrm{~d}, J=8.0$ $\mathrm{Hz}, 1 \mathrm{H}), 6.88(\mathrm{~m}, 1 \mathrm{H}), 6.83(\mathrm{~d}, J=8.1 \mathrm{~Hz}, 1 \mathrm{H}), 4.55(\mathrm{dd}, J=8.4,2.7 \mathrm{~Hz}, 1 \mathrm{H}), 3.87(\mathrm{~m}, 2 \mathrm{H}), 3.60(\mathrm{~m}, 2 \mathrm{H}), 2.19(\mathrm{~m}, 1 \mathrm{H})$, $2.03(\mathrm{~m}, 3 \mathrm{H}), 1.39(\mathrm{~s}, 9 \mathrm{H})$.

${ }^{13}$ C NMR (101 MHz, DMSO) $\delta$ 171.81, 168.46, 156.26, 152.02, 130.76, 126.56, 125.17, 125.06, 124.94, 124.58, $123.62,107.62,78.43,60.73,49.07,29.92,28.66,24.97$.

ESI-MS': m/z: $313.4[\mathrm{M}-\mathrm{Boc}+\mathrm{H}]^{+} ; 413.4[\mathrm{M}+\mathrm{H}]^{+} ; 436[\mathrm{M}+\mathrm{Na}]^{+}$

ESI-MS: $\mathbf{m} / \mathbf{z}: 412[\mathrm{M}-\mathrm{H}]^{-}$

(S)-tert-Butyl (2-(4,4-difluoro-2-((4-hydroxynaphthalen-1-yl)carbamoyl)pyrrolidin-1-yl)-2-oxoethyl)carbamate (30)

(S)-tert-Butyl (2-(4,4-difluoro-2-((4-hydroxynaphthalen-1-yl)carbamoyl)pyrrolidin-1-yl)-2-oxoethyl)carbamate was prepared from $\mathbf{N}$-alpha-t-Boc-glycine and $\mathbf{2 0}$ following general procedure E. The crude product was further purified 
using NP-flash chromatography heptane:EtOAc (80:20) $\rightarrow$ EtOAc (100\%) yielding the title compound as a white crystalline solid.

Yield: $50.4 \%$

${ }^{1} \mathrm{H}$ NMR (400 MHz, DMSO-d $\left.\boldsymbol{d}_{6}\right) \boldsymbol{\delta} 9.67(\mathrm{~s}, 1 \mathrm{H}), 8.05(\mathrm{~m}, 1 \mathrm{H}), 7.81(\mathrm{~m}, 1 \mathrm{H}), 7.44(\mathrm{~m}, 2 \mathrm{H}), 7.12(\mathrm{~d}, J=8.0 \mathrm{~Hz}, 1 \mathrm{H}), 6.92$ $(\mathrm{m}, 1 \mathrm{H}), 6.77(\mathrm{~d}, J=8.0 \mathrm{~Hz}, 1 \mathrm{H}), 4.71(\mathrm{dd}, J=9.5,4.7 \mathrm{~Hz}, 1 \mathrm{H}), 4.04(\mathrm{~m}, 2 \mathrm{H}), 3.75(\mathrm{~m}, 2 \mathrm{H}), 1.29(\mathrm{~s}, 9 \mathrm{H})$.

${ }^{13}$ C NMR (101 MHz, DMSO) $\delta$ 173.11, 171.30, 168.30, 152.22, 150.72 (t, J = 154.5, 58.6 Hz), 149.42, 142.15, 130.31, $130.30,127.84,127.06,126.67,125.34,124.28,123.83,123.08,120.04,108.10,62.14,49.28,25.49$.

ESI-MS : m/z: $450.3[\mathrm{M}+\mathrm{H}]^{+} ; 472.3[\mathrm{M}+\mathrm{Na}]^{+}$

ESI-MS: $\mathbf{m} / \mathbf{z :} 448.0[\mathrm{M}-\mathrm{H}]^{-}$

(S)-tert-Butyl (2-(2-((4-hydroxynaphthalen-1-yl)carbamoyl)pyrrolidin-1-yl)-1-oxopropan-2-yl)carbamate (31)

(S)-tert-Butyl (2-(2-((4-hydroxynaphthalen-1-yl)carbamoyl)pyrrolidin-1-yl)-1-oxopropan-2-yl)carbamate was prepared from Boc-D-ala-OH and 19 following general procedure E. The crude product was further purified using NP-flash chromatography: heptane:EtOAc $(30: 60) \rightarrow$ EtOAc $(100 \%) \rightarrow$ EtOAc:MeOH $(85: 15)$ yielding the title compound as a white crystalline solid.

Yield: $26.3 \%$

${ }^{1} \mathrm{H}$ NMR (400 MHz, MeOD- $\left.d_{4}\right) \delta 8.23(\mathrm{ddd}, J=0.75,1.45,8.36 \mathrm{~Hz}, 1 \mathrm{H}), 7.93(\mathrm{~d}, J=8.39 \mathrm{~Hz}, 1 \mathrm{H}), 7.53$ (ddd, $J=1.43$, 6.80, 8.39 Hz, 1H), 7.46 (ddd, $J=1.28,6.78,8.11 \mathrm{~Hz}, 1 \mathrm{H}), 7.26(\mathrm{~d}, J=8.01 \mathrm{~Hz}, 1 \mathrm{H}), 6.80(\mathrm{~m}, 1 \mathrm{H}), 4.71(\mathrm{dd}, J=3.57$, $8.50 \mathrm{~Hz}, 1 \mathrm{H}), 3.98(\mathrm{~m}, 2 \mathrm{H}), 3.72(\mathrm{~m}, 2 \mathrm{H}), 2.28-2.43(\mathrm{~m}, 1 \mathrm{H}), 2.22(\mathrm{~m}, 3 \mathrm{H}), 2.12(\mathrm{~m}, 1 \mathrm{H}), 1.44(\mathrm{~s}, 9 \mathrm{H})$.

${ }^{13}$ C NMR (101 MHz, MeOD) $\delta$ 173.71, 172.94, 156.75, 152.70, 131.05, 125.28, 124.33, 123.65, 122.66, 122.14, $106.55,79.29,61.26,60.15,47.62,29.47,26.95,24.28,15.08$.

ESI-MS ${ }^{+}: \mathrm{m} / \mathrm{z}: 314.1[\mathrm{M}-\mathrm{Boc}+\mathrm{H}]^{+}, 436.2[\mathrm{M}+\mathrm{Na}]^{+}, 849.5[2 \mathrm{M}+\mathrm{Na}]^{+}$,

ESI-MS: m/z: $412.3[\mathrm{M}-\mathrm{H}]^{-}$

tert-Butyl ((R)-1-((S)-4,4-difluoro-2-((4-hydroxynaphthalen-1-yl)carbamoyl)pyrrolidin-1-yl)-1-oxopropan-2yl)carbamate (32)

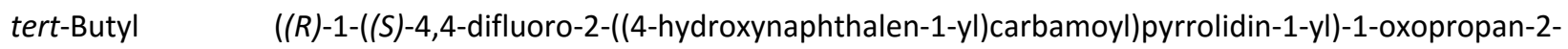
$\mathrm{yl)carbamate}$ was prepared from Boc-D-ala-OH and $\mathbf{2 0}$ following general procedure E. The crude product was further purified using NP-flash chromatography: heptane:EtOAc (1:1) $\rightarrow$ EtOAc yielding the title compound as a beige crystalline solid.

Yield: $35.8 \%$ 
${ }^{1} \mathrm{H}$ NMR $\left(400 \mathrm{MHz}\right.$, Acetone- $\left.d_{6}\right) \delta 9.07(\mathrm{~s}, 1 \mathrm{H}), 9.04(\mathrm{~s}, 1 \mathrm{H}), 8.24(\mathrm{~d}, J=8.1 \mathrm{~Hz}, 1 \mathrm{H}), 8.02(\mathrm{~d}, J=8.5 \mathrm{~Hz}, 1 \mathrm{H}), 7.49(\mathrm{~m}$, 3H), $7.35(\mathrm{~d}, J=8.0 \mathrm{~Hz}, 1 \mathrm{H}), 6.88(\mathrm{~d}, J=8.0 \mathrm{~Hz}, 1 \mathrm{H}), 6.58(\mathrm{~d}, J=5.7 \mathrm{~Hz}, 1 \mathrm{H}), 5.01(\mathrm{dd}, J=8.5,4.6 \mathrm{~Hz}, 1 \mathrm{H}), 4.39(\mathrm{~m}$, $3 \mathrm{H}), 1.03(\mathrm{~s}, 9 \mathrm{H}), 1.45(\mathrm{~d}, J=10.3 \mathrm{~Hz}, 2 \mathrm{H}), 1.38(\mathrm{~d}, J=6.8 \mathrm{~Hz}, 3 \mathrm{H})$.

ESI-MS': m/z: $363[\mathrm{M}-\mathrm{Boc}+\mathrm{H}]^{+} ; 464.3[\mathrm{M}+\mathrm{H}]^{+} ; 486.3[\mathrm{M}+\mathrm{Na}]^{+}$

(S)-1-(2-Aminoacetyl)-N-(4-methyl-2-oxo-2H-chromen-7-yl)pyrrolidine-2-carboxamide 2,2,2-trifluoroacetate (33) (S)-1-(2-Aminoacetyl)-N-(4-methyl-2-oxo-2H-chromen-7-yl)pyrrolidine-2-carboxamide 2,2,2-trifluoroacetate was prepared from $\mathbf{N}$-alpha-t-Boc-Glycine and $\mathbf{1 5}$ following general procedure $\mathrm{E}$, resulting in the Boc-protected proline analogue 21, which was consecutively deprotected following general procedure $D$. The crude product was further purified using RP-flash chromatography: water $\rightarrow$ water:MeCN (50:50) yielding the title compound as a beige amorphous solid.

Yield: $50.3 \%$

${ }^{1} \mathrm{H}$ NMR (400 MHz, DMSO-d $) \delta 10.93(\mathrm{~s}, 1 \mathrm{H}), 8.28(\mathrm{~m}, 3 \mathrm{H}), 7.90(\mathrm{~s}, 1 \mathrm{H}), 7.78(\mathrm{~d}, J=8.7 \mathrm{~Hz}, 1 \mathrm{H}), 7.63(\mathrm{~d}, J=8.4 \mathrm{~Hz}$, $1 \mathrm{H}), 6.34(\mathrm{~d}, J=7.0 \mathrm{~Hz}, 1 \mathrm{H}), 4.63(\mathrm{dd}, J=8.8,3.6 \mathrm{~Hz}, 1 \mathrm{H}), 3.94(\mathrm{~s}, 2 \mathrm{H}), 3.71(\mathrm{~m}, 1 \mathrm{H}), 3.61(\mathrm{~m}, 1 \mathrm{H}), 2.46(\mathrm{~s}, 3 \mathrm{H}), 2.28$ $(\mathrm{m}, 1 \mathrm{H}), 1.98(\mathrm{~m}, 3 \mathrm{H})$.

${ }^{13}$ C NMR (101 MHz, DMSO) $\delta$ 170.82, 164.63, 160.05, 153.60, 153.14, 142.39, 125.85, 115.15 (q, J = 28.28; 257.55 $\mathrm{Hz}), 112.29,105.68,60.47,46.08,30.71,29.57,24.29,18.00$.

ESI-MS': m/z: $330.2[\mathrm{M}+\mathrm{H}]^{+} ; 352.2[\mathrm{M}+\mathrm{Na}]^{+}$

ESI-MS: $\mathbf{m} / \mathrm{z}: 328.2[\mathrm{M}-\mathrm{H}]^{-}$

(S)-1-(2-Aminoacetyl)-4,4-difluoro-N-(4-methyl-2-oxo-2H-chromen-7-yl)pyrrolidine-2-carboxamide 2,2,2trifluoroacetate (34)

(S)-1-(2-Aminoacetyl)-4,4-difluoro-N-(4-methyl-2-oxo-2H-chromen-7-yl)pyrrolidine-2-carboxamide

2,2,2trifluoroacetate was prepared from $\mathrm{N}$-alpha-t-Boc-glycine and $\mathbf{1 5}$ following general procedure $\mathrm{E}$, resulting in the Boc protected proline analogue 22, which was consecutively deprotected following general procedure D. The crude product was further purified using RP-flash chromatography: water $\rightarrow$ water:MeCN (25:75) yielding the title compound as a beige crystalline solid

Yield: $29.1 \%$

${ }^{1} \mathrm{H}$ NMR $\left(400 \mathrm{MHz}\right.$, Acetone- $\left.\boldsymbol{d}_{6}\right) \boldsymbol{\delta} 7.84(\mathrm{~s}, 1 \mathrm{H}), 7.74(\mathrm{dd}, J=16.1,11.6 \mathrm{~Hz}, 1 \mathrm{H}), 7.51(\mathrm{~m}, 2 \mathrm{H}), 6.05(\mathrm{~m}, 1 \mathrm{H}), 4.79(\mathrm{~m}$, $1 \mathrm{H}), 4.14(\mathrm{~m}, 3 \mathrm{H}), 3.11(\mathrm{q}, J=7.3 \mathrm{~Hz}, 2 \mathrm{H}), 2.59(\mathrm{~m}, 2 \mathrm{H}), 2.29(\mathrm{dt}, J=6.8,3.5 \mathrm{~Hz}, 3 \mathrm{H}), 1.23-1.32(\mathrm{~m}, 2 \mathrm{H})$.

${ }^{13}$ C NMR (101 MHz, Acetone) $\delta$ 169.28, 161.47, 160.90, 154.99, 153.48, 142.80, 126.12, 116.94, 116.70, 113.77, $107.86,100.88,60.24,58.12,46.67,38.17,18.44$. 
ESI-MS': m/z: $366.1[\mathrm{M}+\mathrm{H}]^{+} ; 388.0[\mathrm{M}+\mathrm{Na}]^{+}$

(S)-1-((R)-2-Aminopropanoyl)-N-(4-methyl-2-oxo-2H-chromen-7-yl)pyrrolidine-2-carboxamide trifluoroacetate (35)

(S)-1-((R)-2-aminopropanoyl)-N-(4-methyl-2-oxo-2H-chromen-7-yl)pyrrolidine-2-carboxamide

2,2,2trifluoroacetate was prepared from $\mathbf{2 3}$ following general procedure D and was obtained as a beige amorphous solid.

${ }^{1} \mathrm{H}$ NMR (400 MHz, DMSO-d d $\delta 10.54(\mathrm{~s}, 1 \mathrm{H}), 8.11(\mathrm{~m}, 3 \mathrm{H}), 7.71(\mathrm{~d}, J=2.0 \mathrm{~Hz}, 1 \mathrm{H}), 7.64(\mathrm{~d}, J=8.7 \mathrm{~Hz}, 1 \mathrm{H}), 7.41(\mathrm{dd}$, $J=8.7,2.1 \mathrm{~Hz}, 1 \mathrm{H}), 6.18(\mathrm{~s}, 1 \mathrm{H}), 4.42(\mathrm{dd}, J=8.9,2.6 \mathrm{~Hz}, 1 \mathrm{H}), 4.20(\mathrm{~m}, 1 \mathrm{H}), 3.71(\mathrm{ddt}, J=9.7,7.5,3.5 \mathrm{~Hz}, 1 \mathrm{H}), 3.47$ (dt, J= 7.5, 5.9 Hz, 1H), $2.32(\mathrm{~d}, J=1.4 \mathrm{~Hz}, 3 \mathrm{H}), 2.14(\mathrm{~m}, 1 \mathrm{H}), 1.87(\mathrm{~m}, 3 \mathrm{H}), 1.30(\mathrm{~d}, J=6.8 \mathrm{~Hz}, 3 \mathrm{H})$.

${ }^{13}$ C NMR (101 MHz, DMSO) $\delta$ 170.80, 167.86, 159.99, 158.34 (q, J = 36.4, 35.4 Hz), 153.62, 153.04, 142.26, 125.87, $115.19,115.04,114.40$ (q, J=293.9 Hz), 112.30, 10.62, 60.65, 47.20, 46.67, 29.33, 24.23, 17.92, 15.62.

ESI-MS : m/z: $344.2[\mathrm{M}+\mathrm{H}]^{+} ; 366.0[\mathrm{M}+\mathrm{Na}]^{+}$

(S)-1-((R)-2-Aminopropanoyl)-4,4-difluoro-N-(4-methyl-2-oxo-2H-chromen-7-yl)pyrrolidine-2-carboxamide 2,2,2trifluoroacetate (36)

(S)-1-((R)-2-Aminopropanoyl)-4,4-difluoro-N-(4-methyl-2-oxo-2H-chromen-7-yl)pyrrolidine-2-carboxamide 2,2,2trifluoroacetate was prepared from $\mathbf{2 4}$ following general procedure D. The crude product was further purified using RP-flash chromatography water:MeCN (85:15) $\rightarrow$ water:MeCN (20:80) yielding the title compound as a white solid.

Yield: $98 \%$

${ }^{1} \mathrm{H}$ NMR (400 MHz, MeOD- $\left.d_{4}\right) \delta 7.85(\mathrm{~d}, J=2.07 \mathrm{~Hz}, 1 \mathrm{H}), 7.75(\mathrm{~d}, J=8.66 \mathrm{~Hz}, 1 \mathrm{H}), 7.47(\mathrm{dd}, J=2.09,8.70 \mathrm{~Hz}, 1 \mathrm{H})$, $6.27(\mathrm{q}, J=1.12 \mathrm{~Hz}, 1 \mathrm{H}), 4.83(\mathrm{dd}, J=5.43,9.43 \mathrm{~Hz}, 1 \mathrm{H}), 4.29(\mathrm{q}, J=6.82 \mathrm{~Hz}, 1 \mathrm{H}), 4.19(\mathrm{~m}, 2 \mathrm{H}), 2.96(\mathrm{qd}, J=9.42$, $13.88 \mathrm{~Hz}, 1 \mathrm{H}), 2.65$ (qd, $J=5.46,14.49 \mathrm{~Hz}, 1 \mathrm{H}), 2.48$ (d, J=1.27 Hz, 3H), $1.53(\mathrm{~d}, J=6.90 \mathrm{~Hz}, 3 \mathrm{H})$.

${ }^{13}$ C NMR (101 MHz, MeOD) $\delta$ 169.25, 168.62, 161.71, 153.93, 141.63, 125.44, 116.13, 115.67, 112.45, 106.72, 58.92, $53.05,47.39,36.79,17.11,14.73$.

ESI-MS': m/z: 380,1 $[\mathrm{M}+\mathrm{H}]^{+}, 420,1[\mathrm{M}+\mathrm{Na}]^{+}, 759.3[2 \mathrm{M}+\mathrm{H}]^{+}, 781.3[2 \mathrm{M}+\mathrm{Na}]^{+}$

ESI-MS: m/z: $378.1[\mathrm{M}-\mathrm{H}]^{+}$

(S)-1-(2-Aminoacetyl)-N-(4-nitrophenyl)pyrrolidine-2-carboxamide hydrochloride (37)

(S)-1-(2-Aminoacetyl)-N-(4-nitrophenyl)pyrrolidine-2-carboxamide hydrochloride was prepared from 25 following general procedure D. The crude product was redissolved in a minimal amount and a $2 \mathrm{M} \mathrm{HCl}$ solution in dietylether was added in a dropwise manner in order to form an $\mathrm{HCl}$ salt. Further purification by RP-flash chromatography: water $\rightarrow$ MeCN yielding the title compound as a yellow solid. 
Yield: $28.0 \%$

${ }^{1} \mathrm{H}$ NMR (400 MHz, $\left.\mathrm{CDCl}_{3}\right) \delta 10.43(\mathrm{~s}, 1 \mathrm{H}), 8.11(\mathrm{~d}, J=8.62 \mathrm{~Hz}, 2 \mathrm{H}), 7.82(\mathrm{~d}, J=9.02 \mathrm{~Hz}, 2 \mathrm{H}), 4.73(\mathrm{~s}, 1 \mathrm{H}), 3.90(\mathrm{~m}, 1 \mathrm{H})$, $2.76(\mathrm{~m}, 2 \mathrm{H}), 2.12(\mathrm{~m}, 2 \mathrm{H}), 1.62(\mathrm{~m}, 2 \mathrm{H}), 0.95(\mathrm{~s}, 2 \mathrm{H})$.

${ }^{13} \mathrm{C}$ NMR (101 MHz, CDCl $)$ $\delta$ 171.58, 165.93, 144.18, 143.38, 124.74, 119.77, 61.36, 46.77, 29.57, 24.62, 15.46.

ESI-MS : m/z: $293.2[\mathrm{M}+\mathrm{H}]^{+}$

ESI-MS: m/z: $291.3[\mathrm{M}-\mathrm{H}]^{-}$

(S)-1-(2-Aminoacetyl)-4,4-difluoro-N-(4-nitrophenyl)pyrrolidine-2-carboxamide 2,2,2-trifluoroacetate (38)

(S)-1-(2-Aminoacetyl)-4,4-difluoro-N-(4-nitrophenyl)pyrrolidine-2-carboxamide 2,2,2-trifluoroacetate was prepared from 26 following general procedure D and was obtained as a yellow amorphous solid. Product was used without further purification.

Yield: $100 \%$

${ }^{1}$ H NMR (400 MHz, DMSO- $\left.d_{6}\right) \delta 11.15(\mathrm{~s}, 1 \mathrm{H}), 8.24(\mathrm{~m}, 2 \mathrm{H}), 7.91(\mathrm{~m}, 2 \mathrm{H}), 4.83(\mathrm{dd}, J=9.2,5.6 \mathrm{~Hz}, 1 \mathrm{H}), 4.21(\mathrm{~m}, 2 \mathrm{H})$, $3.99(\mathrm{~m}, 2 \mathrm{H}), 2.96(\mathrm{~m}, 1 \mathrm{H}), 2.59(\mathrm{tt}, J=14.1,7.0 \mathrm{~Hz}, 1 \mathrm{H}), 1.09(\mathrm{t}, J=7.0 \mathrm{~Hz}, 2 \mathrm{H})$.

${ }^{13}$ C NMR (101 MHz, DMSO) $\delta$ 169.18, 165.94, 159.42, 159.06, 158.87 (q, J = 37.4 Hz), 158.69, 145.29, 142.94, 125.42, $119.54,117.42,114.53,65.38,58.85,37.43(t, J=24.2 \mathrm{~Hz})$.

ESI-MS : m/z: $329.1[\mathrm{M}+\mathrm{H}]^{+}$

ESI-MS: $\mathbf{m} / \mathbf{z}: 327.1[\mathrm{M}-\mathrm{H}]^{-}$

(S)-1-((R)-2-Aminopropanoyl)-N-(4-nitrophenyl)pyrrolidine-2-carboxamide hydrochloride (39)

(S)-1-((R)-2-Aminopropanoyl)-N-(4-nitrophenyl)pyrrolidine-2-carboxamide hydrochloride was prepared from 27 following general procedure $\mathrm{D}$. The crude product was redissolved in a minimal amount and a $2 \mathrm{M} \mathrm{HCl}$ solution in dietylether was added in a dropwise manner in order to form the $\mathrm{HCl}$ salt as a yellow crystalline solid. The product was used without further purification.

Yield: $77 \%$

${ }^{1} \mathrm{H}$ NMR (400 MHz, MeOD-d d $_{4} \delta 8.24(\mathrm{~m}, 2 \mathrm{H}), 7.86(\mathrm{~m}, 2 \mathrm{H}), 4.59(\mathrm{~m}, 1 \mathrm{H}), 4.33(\mathrm{q}, J=6.92 \mathrm{~Hz}, 1 \mathrm{H}), 3.91(\mathrm{~m}, 1 \mathrm{H}), 3.68$ $(\mathrm{m}, 1 \mathrm{H}), 2.37(\mathrm{~m}, 1 \mathrm{H}), 2.21(\mathrm{~m}, 1 \mathrm{H}), 2.12(\mathrm{~m}, 2 \mathrm{H}), 1.53(\mathrm{~d}, J=6.89 \mathrm{~Hz}, 3 \mathrm{H})$.

${ }^{13}$ C NMR (101 MHz, MeOD) $\delta$ 171.65, 168.21, 144.44, 143.39, 124.36, 119.11, 61.20, 29.36, 24.33, 14.60.

ESI-MS : m/z: $307.1[\mathrm{M}+\mathrm{H}]^{+} ; 613.3[2 \mathrm{M}+\mathrm{H}]^{+}$ 
ESI-MS: $\mathbf{m} / \mathbf{z}: 305.1[\mathrm{M}-\mathrm{H}]^{-}$

(S)-1-((R)-2-Aminopropanoyl)-4,4-difluoro-N-(4-nitrophenyl)pyrrolidine-2-carboxamide

2,2,2-trifluoroacetate (40)

(S)-1-((R)-2-aminopropanoyl)-4,4-difluoro- $N$-(4-nitrophenyl)pyrrolidine-2-carboxamide 2,2,2-trifluoroacetate was prepared from $\mathbf{2 8}$ general procedure D and was obtained as a yellow amorphous solid. Product was used without further purification.

Yield: $100 \%$

${ }^{1} \mathrm{H}$ NMR (400 MHz, DMSO-d d $\delta 10.91(\mathrm{~s}, 1 \mathrm{H}), 8.26(\mathrm{~m}, 2 \mathrm{H}), 7.86(\mathrm{dq}, J=10.2,3.1,2.6 \mathrm{~Hz}, 2 \mathrm{H}), 6.83(\mathrm{broad} \mathrm{s}, 2 \mathrm{H})$, $4.77(\mathrm{dd}, J=9.9,4.0 \mathrm{~Hz}, 1 \mathrm{H}), 4.27(\mathrm{~m}, 2 \mathrm{H}), 4.15(\mathrm{~m}, 1 \mathrm{H}), 2.93(\mathrm{~m}, 2 \mathrm{H}), 2.61(\mathrm{tdd}, J=14.0,9.4,4.3 \mathrm{~Hz}, 1 \mathrm{H}), 1.37(\mathrm{~d}, J=$ $6.9 \mathrm{~Hz}, 3 \mathrm{H})$.

${ }^{13}$ C NMR (101 MHz, DMSO) $\delta$ 169.13, 169.03, 159.04, 158.69, (q, J = 35.0 Hz),145.26, 125.47, 119.57, 117.95, 115.03, 59.09, $53.43(t, J=31.3 \mathrm{~Hz}), 47.51,37.23(t, J=24.2 \mathrm{~Hz}), 16.10$.

ESI-MS : m/z: $343.1[\mathrm{M}+\mathrm{H}]^{+}$

ESI-MS: $\mathbf{m} / \mathbf{z}: 341.1[\mathrm{M}-\mathrm{H}]^{-}$

(S)-1-(2-Aminoacetyl)-N-(4-hydroxynaphthalen-1-yl)pyrrolidine-2-carboxamide 2,2,2-trifluoroacetate (41)

(S)-1-(2-Aminoacetyl)-N-(4-hydroxynaphthalen-1-yl)pyrrolidine-2-carboxamide 2,2,2-trifluoroacetate was prepared from 29 following general procedure D. Product was used without further purification.

Yield: $73.5 \%$

${ }^{1} \mathrm{H}$ NMR (400 MHz, MeOD- $\left.d_{4}\right) \delta 8.25(\mathrm{~m}, 1 \mathrm{H}), 7.97(\mathrm{dt}, J=8.6,0.9 \mathrm{~Hz}, 1 \mathrm{H}), 7.52(\mathrm{ddd}, J=8.4,6.8,1.5 \mathrm{~Hz}, 1 \mathrm{H}), 7.47$ (ddd, $J=8.1,6.8,1.4 \mathrm{~Hz}, 1 \mathrm{H}), 7.27(\mathrm{~d}, J=8.0 \mathrm{~Hz}, 1 \mathrm{H}), 6.83(\mathrm{~d}, J=7.9 \mathrm{~Hz}, 1 \mathrm{H}), 4.75(\mathrm{dd}, J=8.5,4.1 \mathrm{~Hz}, 1 \mathrm{H}), 3.92(\mathrm{~m}$, $2 \mathrm{H}), 3.60(\mathrm{~m}, 2 \mathrm{H}), 2.43(\mathrm{~m}, 1 \mathrm{H}), 2.21(\mathrm{ttd}, J=10.8,5.1,2.8 \mathrm{~Hz}, 2 \mathrm{H}), 2.10(\mathrm{~m}, 1 \mathrm{H})$.

${ }^{13}$ C NMR (101 MHz, MeOD) $\delta$ 172.93, 164.85, 160.66 (q, $J=38.4$ Hz), 152.68, 130.68, 126.24, 125.29, 124.46, 124.29, 123.67, 122.41, 116.44 (q, J = 290.9 Hz), 106.63, 60.65, 46.33, 40.13, 29.76, 24.44.

ESI-MS $:$ m/z: $314.1[\mathrm{M}+\mathrm{H}]^{+}: 336[\mathrm{M}+\mathrm{Na}]^{+} ; 627.3[2 \mathrm{M}+\mathrm{H}]^{+} ; 649.3[2 \mathrm{M}+\mathrm{Na}]^{+} ;$

(S)-1-(2-Aminoacetyl)-4,4-difluoro-N-(4-hydroxynaphthalen-1-yl)pyrrolidine-2-carboxamide hydrochloride (42)

(S)-1-(2-aminoacetyl)-4,4-difluoro- $N$-(4-hydroxynaphthalen-1-yl)pyrrolidine-2-carboxamide hydrochloride was prepared from 30 following general procedure D. The crude product was redissolved in a minimal amount of $\mathrm{MeOH}$ and a $2 \mathrm{M}$ solution of $\mathrm{HCl}$ in diethylether was added dropwise upon precipitate formation. The precipitate was 
filtered of and washed with minimal amounts of diethylether yielding the title compound as a beige solid. Product was used without further purification.

Yield: $96 \%$

${ }^{1} \mathrm{H}$ NMR $\left(400 \mathrm{MHz}\right.$, Acetone- $\left.d_{6}\right) \delta 7.94(\mathrm{~d}, J=8.0 \mathrm{~Hz}, 1 \mathrm{H}), 7.67(\mathrm{~d}, J=4.1 \mathrm{~Hz}, 1 \mathrm{H}), 7.21(\mathrm{~m}, 1 \mathrm{H}), 7.18(\mathrm{~m}, 1 \mathrm{H}), 7.14(\mathrm{~m}$, $1 \mathrm{H}), 7.01(\mathrm{~d}, J=8.1 \mathrm{~Hz}, 1 \mathrm{H}), 6.61(\mathrm{dd}, J=10.9,8.0 \mathrm{~Hz}, 1 \mathrm{H}), 4.72(\mathrm{dd}, J=9.4,4.4 \mathrm{~Hz}, 1 \mathrm{H}), 3.99(\mathrm{~m}, 4 \mathrm{H}), 2.51(\mathrm{~m}, 2 \mathrm{H})$.

${ }^{13}$ C NMR (101 MHz, Acetone) $\delta$ 168.53, 166.08, 151.88, 130.59, 126.30 (t, J = 106.55 Hz), 126.26, 125.06, 124.57, $124.10,122.99,122.25,107.08,65.21,59.15,52.84(t, J=33.1 \mathrm{~Hz}), 37.28(\mathrm{t}, J=24.2 \mathrm{~Hz}$.

ESI-MS ${ }^{+}: \mathbf{m} / \mathbf{z}: 350.2[\mathrm{M}+\mathrm{H}]^{+} ; 372.1[\mathrm{M}+\mathrm{Na}]^{+} ; 699[2 \mathrm{M}+\mathrm{H}]^{+}$

ESI-MS: $\mathbf{m} / \mathbf{z :} 348.2[\mathrm{M}-\mathrm{H}]^{-}$

(S)-1-((R)-2-Aminopropanoyl)-N-(4-hydroxynaphthalen-1-yl)pyrrolidine-2-carboxamide

2,2,2-trifluoroacetate (43)

(S)-1-((R)-2-Aminopropanoyl)-N-(4-hydroxynaphthalen-1-yl)pyrrolidine-2-carboxamide 2,2,2-trifluoroacetate was prepared from $\mathbf{3 1}$ following general procedure D and was obtained as an off-white amorphous solid. Product was used without further purification.

Yield: $100 \%$

${ }^{1} \mathrm{H}$ NMR (400 MHz, DMSO-d $\left.{ }_{6}\right) \delta 9.38(\mathrm{~s}, 1 \mathrm{H}), 7.84(\mathrm{~m}, 1 \mathrm{H}), 7.62(\mathrm{~m}, 2 \mathrm{H}), 7.18(\mathrm{~m}, 2 \mathrm{H}), 6.93(\mathrm{~d}, J=8.0 \mathrm{~Hz}, 1 \mathrm{H}), 6.54(\mathrm{~d}$, $J=8.0 \mathrm{~Hz}, 1 \mathrm{H}), 4.29(\mathrm{dd}, J=8.5,2.6 \mathrm{~Hz}, 1 \mathrm{H}), 3.94(\mathrm{t}, J=8.0,4.0 \mathrm{~Hz}, 1 \mathrm{H}), 3.47(\mathrm{~m}, 1 \mathrm{H}), 3.29(\mathrm{~m}, 1 \mathrm{H}), 2.25(\mathrm{p}, J=1.9 \mathrm{~Hz}$, 1H), 2.20 (p, J=1.9 Hz, 2H), $2.15(p, J=1.9 \mathrm{~Hz}, 1 \mathrm{H}), 1.09$ (d, J=6.8 Hz, 3H).

${ }^{13}$ C NMR (101 MHz, DMSO) $\delta$ 171.31, 168.59, 158.55 (q, J = 35.4, 35.4, 34.3 Hz), 152.10, 130.78, 126.55, 125.18, 125.04, 124.81, 124.65, 123.59 (q, $J=107.1$; 93.9; 110,7Hz), 118.01, 115.09, 107.64, 65.37, 60.87, 47.83, 47.22, $30.16,24.78,16.12$.

ESI-MS $:$ m/z: $328.2[\mathrm{M}+\mathrm{H}]^{+} ; 350.2[\mathrm{M}+\mathrm{Na}]^{+} ; 655.2[2 \mathrm{M}+\mathrm{H}]^{+}$

(S)-1-((R)-2-Aminopropanoyl)-4,4-difluoro-N-(4-hydroxynaphthalen-1-yl)pyrrolidine-2-carboxamide hydrochloride (44)

(S)-1-((R)-2-aminopropanoyl)-4,4-difluoro-N-(4-hydroxynaphthalen-1-yl)pyrrolidine-2-carboxamide hydrochloride was prepared from 32 following general procedure D. The crude product was redissolved in a minimal amount of $\mathrm{MeOH}$ and a $2 \mathrm{M}$ solution of $\mathrm{HCl}$ in diethylether was added dropwise upon precipitate formation. The precipitate was filtered of and washed with minimal amounts of diethylether yielding the title compound as a beige solid. Product was used without further purification. 
Yield: $68.6 \%$

${ }^{1} \mathrm{H}$ NMR $\left(400 \mathrm{MHz}\right.$, Acetone- $\left.d_{6}\right) \delta 7.93(\mathrm{~m}, 1 \mathrm{H}), 7.67(\mathrm{~m}, 1 \mathrm{H}), 7.15(\mathrm{~m}, 2 \mathrm{H}), 6.96(\mathrm{~d}, J=8.0 \mathrm{~Hz}, 1 \mathrm{H}), 6.60(\mathrm{~d}, J=8.0 \mathrm{~Hz}$, $1 \mathrm{H}), 4.69$ (dd, $J=10.0,3.6 \mathrm{~Hz}, 1 \mathrm{H}), 3.93-4.13(\mathrm{~m}, 2 \mathrm{H}), 3.85(\mathrm{q}, J=13.2,12.4 \mathrm{~Hz}, 1 \mathrm{H}), 2.65(\mathrm{q}, J=15.4,14.9 \mathrm{~Hz}, 1 \mathrm{H})$, $2.48(\mathrm{dd}, J=13.1,4.3 \mathrm{~Hz}, 1 \mathrm{H}), 1.24(\mathrm{~d}, J=6.7 \mathrm{~Hz}, 3 \mathrm{H})$.

${ }^{13}$ C NMR (101 MHz, Acetone) $\delta$ 169.56, 168.97, 151.95, 130.89, 126.16, 125.05 (t, J = 139,5; 133.6 Hz), 124.67, 124.54, 123.42, 122.17, 107.23, 59.27, 53.30 (t, J = 32.3; 33.3 Hz), 48.47, 34.45 (t, J = 26.26; 24.24 Hz), 14.71.

ESI-MS : m/z: $364.2[\mathrm{M}+\mathrm{H}]^{+} ; 396.2[\mathrm{M}+\mathrm{Na}]^{+}$

ESI-MS: $\mathbf{m} / \mathbf{z :} 362.2\left[\mathrm{M}-\mathrm{H}^{-}\right.$

(S)-N-(2-(2-((4-Methyl-2-oxo-2H-chromen-7-yl)carbamoyl)pyrrolidin-1-yl)-2-oxoethyl)quinoline-4-carboxamide (6a)

(S)-N-(2-(2-((4-Methyl-2-oxo-2H-chromen-7-yl)carbamoyl)pyrrolidin-1-yl)-2-oxoethyl)quinoline-4-carboxamide was prepared from of $\mathbf{4 6}$ and $\mathbf{3 3}$ following general procedure E. The obtained crude product was further purification by NP-flash chromatography: Heptane: EtOAc $(1: 1) \rightarrow$ EtOAc $(100 \%) \rightarrow$ EtOAc:MeOH (8:2) yielding the title compound as a beige crystalline solid.

Yield: $35.2 \%$

${ }^{1} \mathrm{H}$ NMR (400 MHz, Acetone- $\left.d_{4}\right) \delta 9.57(\mathrm{~s}, 1 \mathrm{H}), 8.44(\mathrm{~d}, J=4.3 \mathrm{~Hz}, 1 \mathrm{H}), 7.98(\mathrm{dd}, J=8.5,0.7 \mathrm{~Hz}, 1 \mathrm{H}), 7.77(\mathrm{t}, J=5.3 \mathrm{~Hz}$, $1 \mathrm{H}), 7.58(\mathrm{~d}, J=8.1 \mathrm{~Hz}, 1 \mathrm{H}), 7.28(\mathrm{~d}, J=1.4 \mathrm{~Hz}, 1 \mathrm{H}), 7.26(\mathrm{t}, J=2.1 \mathrm{~Hz}, 1 \mathrm{H}), 7.25(\mathrm{~d}, J=1.4 \mathrm{~Hz}, 1 \mathrm{H}), 7.17-7.13(\mathrm{~m}, 1 \mathrm{H})$, 7.06 (ddd, $J=8.3,6.9,1.2 \mathrm{~Hz}, 1 \mathrm{H}), 7.02-6.97(\mathrm{~m}, 1 \mathrm{H}), 6.88(\mathrm{~m}, J=8.7,2.1 \mathrm{~Hz}, 1 \mathrm{H}), 5.61(\mathrm{~d}, J=1.2 \mathrm{~Hz}, 2 \mathrm{H}), 4.26(\mathrm{dd}$, $J=7.5,3.2 \mathrm{~Hz}, 1 \mathrm{H}), 3.97(\mathrm{~m}, 2 \mathrm{H}), 3.34(\mathrm{~m}, 2 \mathrm{H}), 1.59(\mathrm{~m}, 5 \mathrm{H})$.

${ }^{13}$ C NMR (101 MHz, Acetone) $\delta$ 171.60, 168.98, 168.37, 160.69, 155.16, 153.28, 150.97, 149.67, 143.04, 142.90, $130.14,127.97,126.77,126.05,125.50,119.92,116.06,113.50,106.99,62.16,49.80,47.50,42.88,25.61,18.39$.

ESI-MS $:$ m/z: $485.5[\mathrm{M}+\mathrm{H}]^{+} ; 507.5[\mathrm{M}+\mathrm{Na}]^{+}$

ESI-MS: $\mathbf{m} / \mathbf{z :} 483.2[\mathrm{M}-\mathrm{H}]^{-}$

(S)-N-(2-(4,4-Difluoro-2-((4-methyl-2-oxo-2H-chromen-7-yl)carbamoyl)pyrrolidin-1-yl)-2-oxoethyl)quinoline-4carboxamide (6b)

(S)-N-(2-(4,4-Difluoro-2-((4-methyl-2-oxo-2H-chromen-7-yl)carbamoyl)pyrrolidin-1-yl)-2-oxoethyl)quinoline-4carboxamide was prepared from $\mathbf{4 6}$ and $\mathbf{3 4}$ following general procedure E. The crude product was further purified by NP-flash chromatography: heptane:EtOAc (40:60) $\rightarrow$ EtOAc $\rightarrow$ EtOAc:MeOH (80:20) yielding the title compound as a white solid. 
Yield: $20.35 \%$

${ }^{1} \mathrm{H}$ NMR (400 MHz, MeOD- $\left.d_{4}\right) \delta 8.97(\mathrm{~d}, J=4.6 \mathrm{~Hz}, 1 \mathrm{H}), 8.41(\mathrm{dt}, J=5.2,2.2 \mathrm{~Hz}, 1 \mathrm{H}), 8.09(\mathrm{~d}, J=8.5 \mathrm{~Hz}, 1 \mathrm{H}), 7.86$ (ddd, $J=8.4,7.0,1.3 \mathrm{~Hz}, 1 \mathrm{H}), 7.76(\mathrm{~d}, J=2.0 \mathrm{~Hz}, 1 \mathrm{H}), 7.74(\mathrm{~d}, J=2.6 \mathrm{~Hz}, 1 \mathrm{H}), 7.68(\mathrm{~m}, 1 \mathrm{H}), 7.64(\mathrm{~m}, 1 \mathrm{H}), 7.47(\mathrm{dd}, J=$ 8.7, $2.1 \mathrm{~Hz}, 1 \mathrm{H}), 6.20(\mathrm{~d}, J=1.2 \mathrm{~Hz}, 1 \mathrm{H}), 4.48(\mathrm{~d}, J=16.9 \mathrm{~Hz}, 1 \mathrm{H}), 4.31(\mathrm{~m}, 2 \mathrm{H}), 4.24(\mathrm{~m}, 1 \mathrm{H}), 3.77(\mathrm{~m}, 1 \mathrm{H}), 2.93(\mathrm{~m}$, $1 \mathrm{H}), 2.64(\mathrm{~m}, 1 \mathrm{H}), 2.42(\mathrm{~d}, J=1.2 \mathrm{~Hz}, 3 \mathrm{H})$.

${ }^{13}$ C NMR (101 MHz, MeOD) $\delta$ 170.76, 169.77, 169.59, 162.97, 155.08, 150.13, 147.48, 145.22, 142.92, 132.28, $129.31,128.23,127.06,126.59,126.07,120.43,117.27$, 117.09, 113.67, 108.03, 60.35, 54.18, 43.04, 38.15, 18.42.

ESI-MS $:$ m/z: $521.2[\mathrm{M}+\mathrm{H}]^{+} ; 543.2[\mathrm{M}+\mathrm{Na}]^{+} ; 1063,4[2 \mathrm{M}+\mathrm{Na}]^{+}$

ESI-MS: m/z: $519.2[M-H]^{-}$

ESI-HRMS ${ }^{+}: \mathrm{C}_{27} \mathrm{H}_{23} \mathrm{~N}_{4} \mathrm{O}_{5} \mathrm{~F}_{2}$; calculated m/z: $521.1637[\mathrm{M}+\mathrm{H}]^{+}$; found: 521.1636 .

N-((R)-1-((S)-2-((4-Methyl-2-oxo-2H-chromen-7-yl)carbamoyl)pyrrolidin-1-yl)-1-oxopropan-2-yl)quinoline-4carboxamide (4, ARI-3144)

$N$-((R)-1-((S)-2-((4-Methyl-2-oxo-2H-chromen-7-yl)carbamoyl)pyrrolidin-1-yl)-1-oxopropan-2-yl)quinoline-4carboxamide was prepared from $\mathbf{4 6}$ and $\mathbf{3 5}$ following general procedure $\mathrm{E}$. The crude product was further purified by NP-flash chromatography: DCM $\rightarrow$ DCM:MeOH (80:20) yielding the title compound as a white crystalline solid.

Yield: $32.2 \%$

${ }^{1} \mathrm{H}$ NMR $\left(400 \mathrm{MHz}, \mathrm{MeOD}-\mathrm{d}_{4}\right) \delta 8.92(\mathrm{~d}, J=4.4 \mathrm{~Hz}, 1 \mathrm{H}), 8.23(\mathrm{~m}, 1 \mathrm{H}), 8.07(\mathrm{~m}, 1 \mathrm{H}), 7.84(\mathrm{~d}, J=2.0 \mathrm{~Hz}, 1 \mathrm{H}), 7.78$ (ddd, $J=8.4,6.9,1.4 \mathrm{~Hz}, 1 \mathrm{H}), 7.64(\mathrm{~d}, J=4.4 \mathrm{~Hz}, 1 \mathrm{H}), 7.54(\mathrm{~m}, 1 \mathrm{H}), 7.49(\mathrm{~d}, J=2.0 \mathrm{~Hz}, 1 \mathrm{H}), 7.47(\mathrm{~d}, J=2.0 \mathrm{~Hz}, 1 \mathrm{H}), 7.44(\mathrm{~s}$, $1 \mathrm{H}), 6.15(\mathrm{dd}, J=5.3,1.2 \mathrm{~Hz}, 1 \mathrm{H}), 5.51(\mathrm{~s}, 1 \mathrm{H}), 5.02(\mathrm{q}, J=7.0 \mathrm{~Hz}, 1 \mathrm{H}), 4.67(\mathrm{dd}, J=8.4,3.7 \mathrm{~Hz}, 1 \mathrm{H}), 4.18(\mathrm{~m}, 1 \mathrm{H}), 3.90$ - $3.79(\mathrm{~m}, 1 \mathrm{H}), 2.44(\mathrm{~d}, J=1.2 \mathrm{~Hz}, 1 \mathrm{H}), 2.35(\mathrm{~d}, J=1.2 \mathrm{~Hz}, 3 \mathrm{H}), 2.18(\mathrm{~m}, 4 \mathrm{H}), 1.52(\mathrm{~d}, J=7.0 \mathrm{~Hz}, 3 \mathrm{H})$.

${ }^{13}$ C NMR (101 MHz, MeOD) $\delta$ 173.91, 173.02, 169.88, 163.29, 155.30, 155.28, 151.15, 149.27, 143.92, 143.40, $131.69,129.74,129.05,127.11,126.57,126.23,120.55,117.48,117.25,113.73,108.31,63.24,49.85,49.74,49.64$, $49.43,49.21,49.00,48.79,48.57,31.02,30.98,25.97,18.69,16.49$.

ESI-MS ${ }^{+}: \mathbf{m} / \mathbf{z}: 499.3[\mathrm{M}+\mathrm{H}]^{+}, 521.0[\mathrm{M}+\mathrm{Na}]^{+}$

ESI-MS: $\mathrm{m} / \mathrm{z}: 497.3[\mathrm{M}-\mathrm{H}]^{-}$

ESI-HRMS': C28H27N4O5; calculated m/z: 499.1981 [M+H]+; found: 499.1996.

$N-((R)-1-((S)-4,4-D i f l u o r o-2-((4-m e t h y l-2-o x o-2 H-c h r o m e n-7-y l)$ carbamoyl)pyrrolidin-1-yl)-1-oxopropan-2yl)quinoline-4-carboxamide (6c) 
N-((R)-1-((S)-4,4-Difluoro-2-((4-methyl-2-oxo-2H-chromen-7-yl)carbamoyl)pyrrolidin-1-yl)-1-oxopropan-2-

$\mathrm{yl}$ )quinoline-4-carboxamide was prepared from $\mathbf{4 6}$ and $\mathbf{3 6}$ following general procedure $E$. The crude product was further purified by NP-flash chromatography: DCM $\rightarrow$ DCM:MeOH (90:10) yielding the title compound as a beige crystalline solid.

Yield: $34.1 \%$

${ }^{1} \mathrm{H}$ NMR (400 MHz, $\left.\mathrm{CDCl}_{3}\right) \delta 9.35(\mathrm{~s}, 1 \mathrm{H}), 8.75(\mathrm{~d}, J=4.3 \mathrm{~Hz}, 1 \mathrm{H}), 8.10(\mathrm{~m}, 1 \mathrm{H}), 7.98(\mathrm{~m}, 1 \mathrm{H}), 7.75(\mathrm{dd}, J=5.3,2.4 \mathrm{~Hz}$, $1 \mathrm{H}), 7.70(\mathrm{~d}, J=2.1 \mathrm{~Hz}, 1 \mathrm{H}), 7.62(\mathrm{ddd}, J=8.5,6.9,1.4 \mathrm{~Hz}, 1 \mathrm{H}), 7.39(\mathrm{~m}, 3 \mathrm{H}), 7.12(\mathrm{~d}, J=8.7 \mathrm{~Hz}, 1 \mathrm{H}), 5.95(\mathrm{~m}, 1 \mathrm{H})$, $4.98(\mathrm{dd}, J=9.5,4.6 \mathrm{~Hz}, 1 \mathrm{H}), 4.76(\mathrm{~m}, 1 \mathrm{H}), 4.08(\mathrm{~m}, 2 \mathrm{H}), 2.73$ (qd, $J=14.2,9.3 \mathrm{~Hz}, 2 \mathrm{H}), 2.19(\mathrm{~d}, J=1.3 \mathrm{~Hz}, 3 \mathrm{H}), 1.53$ $(d, J=6.9 \mathrm{~Hz}, 3 \mathrm{H})$.

${ }^{13} \mathrm{C} \mathrm{NMR}\left(101 \mathrm{MHz}, \mathrm{CDCl}_{3}\right)$ ) 172.17, 168.23, 168.09, 161.25, 153.74, 152.56, 149.57, 148.15, 141.15, 140.77, 130.26, $129.46,127.95,126.14(t, J=251.2 \mathrm{~Hz}), 127.17,124.85,118.86,116.14,116.05,113.19,107.57,60.51,59.17,54.02$ $(\mathrm{t}, J=32.5 \mathrm{~Hz}), 37.04(\mathrm{t}, J=24.7 \mathrm{~Hz}), 18.51,16.41$

ESI-MS': m/z: $535.2[\mathrm{M}+\mathrm{H}]^{+} ; 1091.4[2 \mathrm{M}+\mathrm{Na}]^{+}$

ESI-MS: m/z: $533.1[\mathrm{M}-\mathrm{H}]^{-}$

ESI-HRMS': C28H25N4O5F2; calculated m/z: $535.1793[\mathrm{M}+\mathrm{H}]^{+}$; found: 535.1799.

(S)-N-(2-(2-((4-Nitrophenyl)carbamoyl)pyrrolidin-1-yl)-2-oxoethyl)quinoline-4-carboxamide (6d)

(S)-N-(2-(2-((4-Nitrophenyl)carbamoyl)pyrrolidin-1-yl)-2-oxoethyl)quinoline-4-carboxamide was prepared from 46 and $\mathbf{3 7}$ following general procedure E. The crude product was further purified using NP-flash chromatography: EtOAc $\rightarrow$ EtOAc:MeOH (90:10) yielding the title compound as a brown crystalline solid.

Yield: $27.8 \%$

${ }^{1} \mathrm{H}$ NMR $\left(400 \mathrm{MHz}, \mathrm{CDCl}_{3}\right) \delta 10.27(\mathrm{~s}, 1 \mathrm{H}), 9.18(\mathrm{~d}, J=4.89 \mathrm{~Hz}, 1 \mathrm{H}), 8.31(\mathrm{~m}, 3 \mathrm{H}), 7.96(\mathrm{~d}, J=8.60 \mathrm{~Hz}, 3 \mathrm{H}), 7.82(\mathrm{dd}, J$ $=6.45,8.32 \mathrm{~Hz}, 1 \mathrm{H}), 7.73(\mathrm{~d}, J=8.96 \mathrm{~Hz}, 2 \mathrm{H}), 7.65(\mathrm{t}, J=7.52 \mathrm{~Hz}, 1 \mathrm{H}), 4.90-4.94(\mathrm{~m}, 1 \mathrm{H}), 4.35(\mathrm{~d}, J=5.00 \mathrm{~Hz}, 2 \mathrm{H})$, $3.12(m, 2 \mathrm{H}), 2.97(m, 1 \mathrm{H}), 1.42(\mathrm{t}, J=7.34 \mathrm{~Hz}, 3 \mathrm{H})$,.

${ }^{13} \mathrm{C} \mathrm{NMR}\left(101 \mathrm{MHz}, \mathrm{CDCl}_{3}\right)$ $\delta$ 173.56, 170.48, 167.9, 165.63, 145.96, 144.03, 143.09, 133.38, 129.83, 126.28, 125.35, $124.70,120.07,119.12,61.39,45.87,42.44,29.71,24.95$.

ESI-MS ${ }^{+}: \mathrm{m} / \mathrm{z}: 448.4[\mathrm{M}+\mathrm{H}]^{+} ; 470.4[\mathrm{M}+\mathrm{Na}]^{+}$

ESI-MS: $\mathrm{m} / \mathrm{z}: 446.2[\mathrm{M}-\mathrm{H}]^{-}$

ESI-HRMS': C23H22N5O5; calculated m/z: $448.1621[\mathrm{M}+\mathrm{H}]^{+}$; found: 448.1622. 
(S)-N-(2-(4,4-Difluoro-2-((4-nitrophenyl)carbamoyl)pyrrolidin-1-yl)-2-oxoethyl)quinoline-4-carboxamide (6e)

(S)-N-(2-(4,4-Difluoro-2-((4-nitrophenyl)carbamoyl)pyrrolidin-1-yl)-2-oxoethyl)quinoline-4-carboxamide

was

prepared from $\mathbf{4 6}$ and $\mathbf{3 8}$ following general procedure E and was obtained as a beige amorphous solid.

Yield: $78 \%$

${ }^{1} \mathrm{H}$ NMR (400 MHz, DMSO-d $\left.)_{6}\right) 10.73(\mathrm{~s}, 1 \mathrm{H}), 9.00(\mathrm{t}, J=6.1 \mathrm{~Hz}, 1 \mathrm{H}), 8.89(\mathrm{~d}, J=4.3 \mathrm{~Hz}, 1 \mathrm{H}), 8.22(\mathrm{~d}, J=1.2 \mathrm{~Hz}, 1 \mathrm{H})$, $8.16(\mathrm{~d}, J=9.3 \mathrm{~Hz}, 2 \mathrm{H}), 7.99(\mathrm{~d}, J=8.5, \mathrm{~Hz}, 1 \mathrm{H}), 7.77$ (d, J=9.3 Hz, 2H), $7.69(\mathrm{~m}, 1 \mathrm{H}), 7.55$ (ddd, J=8.3, 6.9, 1.3 Hz, $1 \mathrm{H}), 7.46(\mathrm{~d}, J=4.3 \mathrm{~Hz}, 1 \mathrm{H}), 4.71(\mathrm{dd}, J=9.3,5.3 \mathrm{~Hz}, 1 \mathrm{H}), 4.30(\mathrm{~m}, 2 \mathrm{H}), 4.15(\mathrm{~m}, 1 \mathrm{H}), 4.03(\mathrm{dd}, J=17.0,5.4 \mathrm{~Hz}, 1 \mathrm{H})$, $2.84(\mathrm{~m}, 2 \mathrm{H}), 2.50(\mathrm{~m}, 1 \mathrm{H})$.

${ }^{13}$ C NMR (101 MHz, DMSO) $\delta$ 169.16, 167.55, 167.18, 150.21, 147.84, 144.80, 142.40, 141.97, 129.81, $129.21,127.20$ $(t, J=59.6 ; 63.6 \mathrm{~Hz}), 125.01,124.12,119.03,59.74,58.38,41.39,36.86$.

ESI-MS $:$ m/z: $484.3[\mathrm{M}+\mathrm{H}]^{+}$

ESI-MS: m/z: $482.3[\mathrm{M}-\mathrm{H}]^{-}$

ESI-HRMS+: C23H20N5O5F2; calculated m/z: $484.1433[\mathrm{M}+\mathrm{H}]^{+}$; found: 484.1446.

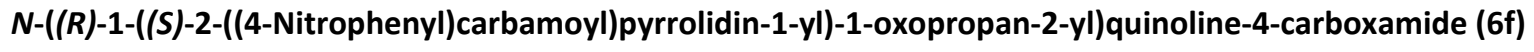

$N$-((R)-1-((S)-2-((4-Nitrophenyl)carbamoyl)pyrrolidin-1-yl)-1-oxopropan-2-yl)quinoline-4-carboxamide was prepared from 46 and 39 following general procedure E. The crude product was further purified by NP-flash chromatography: $E t O A c \rightarrow E t O A c: M e O H(85: 15)$ yielding the title compound as a white solid.

Yield: $47.1 \%$

${ }^{1} \mathrm{H}$ NMR (400 MHz, $\left.\mathrm{CDCl}_{3}\right) \delta 9.46(\mathrm{~s}, 1 \mathrm{H}), 8.84(\mathrm{~d}, J=4.21 \mathrm{~Hz}, 1 \mathrm{H}), 8.09(\mathrm{~m}, 2 \mathrm{H}), 7.92(\mathrm{~m}, 2 \mathrm{H}), 7.80(\mathrm{~m}, 2 \mathrm{H}), 7.68(\mathrm{ddd}$, $J=1.39,6.92,8.44 \mathrm{~Hz}, 1 \mathrm{H}), 7.53(\mathrm{~d}, J=5.40 \mathrm{~Hz}, 1 \mathrm{H}), 7.43(\mathrm{~d}, J=4.30 \mathrm{~Hz}, 1 \mathrm{H}), 7.40(\mathrm{ddd}, J=1.17,6.89,8.29 \mathrm{~Hz}, 1 \mathrm{H})$, $4.86(\mathrm{~m}, 1 \mathrm{H}), 4.10(\mathrm{q}, J=7.14 \mathrm{~Hz}, 1 \mathrm{H}), 3.64(\mathrm{dt}, J=8.00,12.83 \mathrm{~Hz}, 1 \mathrm{H}), 2.45(\mathrm{~m}, 1 \mathrm{H}), 2.11(\mathrm{~m}, 3 \mathrm{H}), 1.53(\mathrm{~d}, J=6.97$ $\mathrm{Hz}, 3 \mathrm{H}), 1.38(\mathrm{~m}, 1 \mathrm{H})$,

${ }^{13} \mathrm{C}$ NMR (101 MHz, CDCl $)$ ) 172.79, 170.29, 170.02, 168.11, 149.30, 147.80, 144.24, 144.01, 143.25, 143.23, 141.23, $130.45,129.23,127.92,125.12,124.64,119.49,118.70,61.62,48.72,47.50,28.87,24.43,16.23$.

ESI-MS $:$ m/z: $462[\mathrm{M}+\mathrm{H}]^{+} ; 484[\mathrm{M}+\mathrm{Na}]^{+} ; 923[2 \mathrm{M}+\mathrm{H}]^{+} ; 945[2 \mathrm{M}+\mathrm{Na}]^{+}$

ESI-MS: $\mathbf{m} / \mathbf{z}: 460[\mathrm{M}-\mathrm{H}]^{-}$

ESI-HRMS': C24H24N5O5; calculated m/z: 462.1777 [M+H] $]^{+}$; found: 462.1785. 
$N-((R)-1-((S)-4,4-D i f l u o r o-2-((4-n i t r o p h e n y l) c a r b a m o y l) p y r r o l i d i n-1-y l)-1-o x o p r o p a n-2-y l) q u i n o l i n e-4-$ carboxamide $(6 \mathrm{~g})$

$N$-((R)-1-((S)-4,4-Difluoro-2-((4-nitrophenyl)carbamoyl)pyrrolidin-1-yl)-1-oxopropan-2-yl)quinoline-4-carboxamide was prepared from $\mathbf{4 6}$ and $\mathbf{4 0}$ following general procedure $\mathrm{E}$. The crude product was further purified using NP-flash chromatography: DCM $\rightarrow$ DCM:MeOH (90:10) yielding the title compound as a beige amorphous solid.

Yield: $65.8 \%$

${ }^{1} \mathrm{H}$ NMR $\left(400 \mathrm{MHz}\right.$, Acetone- $\left.d_{6}\right) \delta 9.62(\mathrm{~m}, 1 \mathrm{H}), 8.96(\mathrm{~d}, J=4.3 \mathrm{~Hz}, 1 \mathrm{H}), 8.72(\mathrm{~m}, 1 \mathrm{H}), 8.22(\mathrm{ddd}, J=8.4,1.4,0.7 \mathrm{~Hz}$, $1 \mathrm{H}), 8.08$ (ddd, $J=8.5,1.3,0.7 \mathrm{~Hz}, 1 \mathrm{H}$ ), $8.01(\mathrm{~s}, 4 \mathrm{H}), 7.75$ (ddd, $J=8.4,6.9,1.4 \mathrm{~Hz}, 1 \mathrm{H}), 7.61(\mathrm{~d}, J=4.3 \mathrm{~Hz}, 1 \mathrm{H}), 7.46$ (ddd, $J=8.3,6.9,1.3 \mathrm{~Hz}, 1 \mathrm{H}$ ), $5.02(\mathrm{dd}, J=9.7,3.6 \mathrm{~Hz}, 1 \mathrm{H}$ ), 4.87 (qd, $J=7.0,4.7 \mathrm{~Hz}, 1 \mathrm{H}$ ), 4.58 (dddd, $J=14.4,11.9$, 9.0, 1.2 Hz, 1H), $4.44(\mathrm{~m}, 1 \mathrm{H}), 2.99(\mathrm{~m}, 1 \mathrm{H}), 2.84(\mathrm{~m}, 1 \mathrm{H}), 1.55(\mathrm{~d}, J=6.9 \mathrm{~Hz}, 3 \mathrm{H})$.

${ }^{13}$ C NMR (101 MHz, Acetone) $\delta$ 173.03, 170.01, 169.53, 150.93, 149.53, 145.40, 144.16, 147.79, 130.62, 130.58, 128.10, 126.41, 125.31, 125.26, 120.35, 119.97, 60.06, 54.53 (t, $J=33.32 ; 32.32 \mathrm{~Hz}), 49.65,37.86$ (t, $J=24.24 \mathrm{~Hz})$, 15.83.

ESI-MS': m/z: $498.2[M+H]^{+}$

ESI-MS: m/z: $496.1[M-H]^{-}$

ESI-HRMS': C24H22N5O5F2; calculated m/z: $498.4589[\mathrm{M}+\mathrm{H}]^{+}$; found: 498.4599.

(S)-N-(2-(2-((4-Hydroxynaphthalen-1-yl)carbamoyl)pyrrolidin-1-yl)-2-oxoethyl)quinoline-4-carboxamide (6h)

(S)-N-(2-(2-((4-Hydroxynaphthalen-1-yl)carbamoyl)pyrrolidin-1-yl)-2-oxoethyl)quinoline-4-carboxamide was prepared from $\mathbf{5 0}$ and $\mathbf{4 1}$ following general procedure E. The crude product was further purified using NP-flash chromatography: DCM $\rightarrow$ DCM:MeOH (90:10) yielding the title compound as a beige solid.

Yield: $40.6 \%$

${ }^{1} \mathrm{H}$ NMR (400 MHz, DMSO-d $\left.\mathrm{d}_{6}\right) \delta 10.16(\mathrm{~s}, 1 \mathrm{H}), 9.00(\mathrm{~d}, J=4.3 \mathrm{~Hz}, 1 \mathrm{H}), 8.44(\mathrm{ddt}, J=8.4,1.1 \mathrm{~Hz}, 1 \mathrm{H}), 8.15(\mathrm{~m}, 1 \mathrm{H}), 8.10$ $(\mathrm{m}, 2 \mathrm{H}), 7.94(\mathrm{~m}, 2 \mathrm{H}), 7.83$ (ddd, $J=8.4,6.8,1.5 \mathrm{~Hz}, 2 \mathrm{H}$ ), 7.65 (ddd, $J=8.3,6.8,1.3 \mathrm{~Hz}, 1 \mathrm{H}$ ), 7.59 (dd, $J=4.4,1.7 \mathrm{~Hz}$, $2 \mathrm{H}), 7.27(\mathrm{~d}, J=8.2,1.0 \mathrm{~Hz}, 1 \mathrm{H}), 6.84(\mathrm{dd}, J=8.0,2.2 \mathrm{~Hz}, 1 \mathrm{H}), 4.65(\mathrm{dd}, J=8.4,2.8 \mathrm{~Hz}, 1 \mathrm{H}), 4.36(\mathrm{~m}, 2 \mathrm{H}), 3.79(\mathrm{td}, J=$ 8.3, 7.3, 2.5 Hz, 1H), $3.51(\mathrm{~m}, 1 \mathrm{H}), 2.25(\mathrm{dtd}, J=13.8,9.8,9.1,5.0 \mathrm{~Hz}, 2 \mathrm{H}), 1.18(\mathrm{~m}, 2 \mathrm{H})$,

${ }^{13}$ C NMR (101 MHz, DMSO) $\delta$ 207.01, 171.68, 167.69, 151.98, 150.72, 148.38, 142.73, 130.70, 130.31, 129.70, $127.63,126.57,126.42,125.17,125.08,124.75,124.49,123.67,122.62,119.53,107.64,60.83,55.40,31.18$, 29.99, 25.03. 
ESI-MS ${ }^{+}: \mathbf{m} / z: 469.2[\mathrm{M}+\mathrm{H}]^{+} ; 491[\mathrm{M}+\mathrm{Na}]^{+} ; 937.4[2 \mathrm{M}+\mathrm{H}]^{+}$

ESI-MS: m/z: $467.2[\mathrm{M}-\mathrm{H}]^{-}$

ESI-HRMS': C27H25N4O4; calculated m/z: 469.1876 [M+H] ${ }^{+}$; found: 469.188.

(S)-N-(2-(4,4-Difluoro-2-((4-hydroxynaphthalen-1-yl)carbamoyl)pyrrolidin-1-yl)-2-oxoethyl)quinoline-4carboxamide (6i)

(S)-N-(2-(4,4-Difluoro-2-((4-hydroxynaphthalen-1-yl)carbamoyl)pyrrolidin-1-yl)-2-oxoethyl)quinoline-4-

carboxamide was prepared from $\mathbf{4 6}$ and $\mathbf{4 2}$ following general procedure E. The crude product was further purified by NP preparitive TLC $\rightarrow$ DCM:MeOH $(90: 10)$ yielding the title compound as a yellow solid.

Yield: $6 \%$

${ }^{1} \mathrm{H}$ NMR (400 MHz, Acetone- $\left.d_{6}\right) \delta 9.35(\mathrm{~s}, 1 \mathrm{H}), 8.97(\mathrm{~d}, J=4.3 \mathrm{~Hz}, 1 \mathrm{H}), 8.45(\mathrm{~d}, J=8.5 \mathrm{~Hz}, 1 \mathrm{H}), 8.26(\mathrm{~m}, 2 \mathrm{H}), 8.10(\mathrm{~d}, J$ $=8.7 \mathrm{~Hz}, 1 \mathrm{H}), 8.06(\mathrm{~m}, 1 \mathrm{H}), 7.79(\mathrm{ddd}, J=8.5,6.9,1.4 \mathrm{~Hz}, 1 \mathrm{H}), 7.63(\mathrm{~d}, J=4.2 \mathrm{~Hz}, 1 \mathrm{H}), 7.57(\mathrm{~m}, J=8.4,6.9,1.3 \mathrm{~Hz}$, 1H), $7.51(\mathrm{~m}, 1 \mathrm{H}), 7.48(\mathrm{~m}, 1 \mathrm{H}), 7.43(\mathrm{~m}, 1 \mathrm{H}), 6.90(\mathrm{~d}, J=8.1 \mathrm{~Hz}, 1 \mathrm{H}), 5.11(\mathrm{dd}, J=8.9,4.9 \mathrm{~Hz}, 1 \mathrm{H}), 4.52(\mathrm{~m}, 2 \mathrm{H}), 4.48$ (m, 2H), $3.02(\mathrm{~m}, J=18.3,5.0 \mathrm{~Hz}, 1 \mathrm{H}), 2.90(\mathrm{~d}, J=3.1 \mathrm{~Hz}, 1 \mathrm{H})$

${ }^{13}$ C NMR (101 MHz, Acetone) $\delta$ 169.82, 169.47, 168.31, 152.30 , 150.95, 149.55, 142.75, 130.89, 130.47, 128.00, $127.26,126.81,125.89,125.75,125.52,125.49,124.07,123.53,123.17,119.91,107.96,59.94,53.89$ (t, $J=32.3 \mathrm{~Hz})$, $42.85,37.48(t, J=24.37 \mathrm{~Hz})$.

ESI-MS $: \mathrm{m} / \mathrm{z}: 505.2[\mathrm{M}+\mathrm{H}]^{+}$

ESI-MS: $\mathbf{m} / \mathbf{z :} 503.2[\mathrm{M}-\mathrm{H}]^{-}$

N-((R)-1-((S)-2-((4-Hydroxynaphthalen-1-yl)carbamoyl)pyrrolidin-1-yl)-1-oxopropan-2-yl)quinoline-4carboxamide (6j)

N-((R)-1-((S)-2-((4-Hydroxynaphthalen-1-yl)carbamoyl)pyrrolidin-1-yl)-1-oxopropan-2-yl)quinoline-4-carboxamide was prepared from $\mathbf{4 6}$ and $\mathbf{4 3}$ following general procedure E. The crude product was further purified by NP-flash chromatography: DCM $\rightarrow$ DCM:MeOH (90:10) yielding the title compound as a white solid.

Yield: $25.6 \%$

${ }^{1} \mathrm{H}$ NMR (400 MHz, Acetone- $\left.d_{6}\right) \delta 9.12(\mathrm{~s}, 1 \mathrm{H}), 8.89(\mathrm{~s}, 1 \mathrm{H}), 8.71(\mathrm{~d}, J=4.3 \mathrm{~Hz}, 1 \mathrm{H}), 8.23(\mathrm{~d}, J=5.6 \mathrm{~Hz}, 1 \mathrm{H}), 8.04(\mathrm{ddd}$, $J=8.5,1.4,0.7 \mathrm{~Hz}, 1 \mathrm{H}), 7.99(\mathrm{ddd}, J=8.5,1.4,0.7 \mathrm{~Hz}, 1 \mathrm{H}), 7.90(\mathrm{~m}, 1 \mathrm{H}), 7.85(\mathrm{ddd}, J=8.6,1.2,0.6 \mathrm{~Hz}, 1 \mathrm{H}), 7.51(\mathrm{ddd}$, $J=8.4,6.9,1.4 \mathrm{~Hz}, 1 \mathrm{H}), 7.34(\mathrm{~d}, J=4.3 \mathrm{~Hz}, 1 \mathrm{H}), 7.31$ (d, $J=7.4 \mathrm{~Hz}, 1 \mathrm{H}), 7.20$ (ddd, J = 8.3, 6.8, $1.2 \mathrm{~Hz}, 1 \mathrm{H}), 7.12(\mathrm{ddd}$, $J=8.3,6.8,1.4 \mathrm{~Hz}, 1 \mathrm{H}), 7.02(\mathrm{ddd}, J=8.3,6.9,1.3 \mathrm{~Hz}, 1 \mathrm{H}), 6.67(\mathrm{~d}, J=8.0 \mathrm{~Hz}, 1 \mathrm{H}), 4.85(\mathrm{qd}, J=6.9,5.7 \mathrm{~Hz}, 1 \mathrm{H}), 4.07$ 
(tdd, $J=7.4,4.9,2.8 \mathrm{~Hz}, 1 \mathrm{H}), 3.91(\mathrm{q}, J=7.1 \mathrm{~Hz}, 1 \mathrm{H}), 3.74(\mathrm{~m}, 1 \mathrm{H}), 2.26(\mathrm{~m}, 1 \mathrm{H}), 2.10(\mathrm{~m}, 2 \mathrm{H}), 1.40(\mathrm{~d}, J=6.9 \mathrm{~Hz}$, $3 \mathrm{H}), 1.15(\mathrm{~m}, 2 \mathrm{H})$,

${ }^{13}$ C NMR (101 MHz, Acetone) $\delta$ 173.11, 171.32, 168.31, 152.23, 150.72, 149.41, 142.15, 131.19, 130.30, 127.84, 127.06, 126.67, 126.51, 126.02, 125.35, 124.29, 123.83, 123.08, 120.04, 108.10, 62.14, 49.28, 48.13, 25.49, 16.55 .

ESI-MS ${ }^{+}: \mathrm{m} / \mathrm{z}: 483.2[\mathrm{M}+\mathrm{H}]^{+} ; 505[\mathrm{M}+\mathrm{Na}]^{+}$

ESI-MS: m/z: $481.2[\mathrm{M}-\mathrm{H}]^{-}$

ESI-HRMS': C28H27N4O4 calculated m/z: $483.2032[\mathrm{M}+\mathrm{H}]^{+}$; found: 483.2011.

N-((R)-1-((S)-4,4-Difluoro-2-((4-hydroxynaphthalen-1-yl)carbamoyl)pyrrolidin-1-yl)-1-oxopropan-2-yl)quinoline4-carboxamide (6k)

N-((R)-1-((S)-4,4-Difluoro-2-((4-hydroxynaphthalen-1-yl)carbamoyl)pyrrolidin-1-yl)-1-oxopropan-2-yl)quinoline-4carboxamide was prepared from $\mathbf{4 6}$ and $\mathbf{4 4}$ following general procedure E. The crude product was further purified using NP preparitive TLC: DCM:MeOH (95:5) yielding the title compound as a yellow amorphous solid.

Yield: $19.2 \%$

${ }^{1} \mathrm{H}$ NMR $\left(400 \mathrm{MHz}\right.$, Acetone- $\left.d_{6}\right) \delta 9.22(\mathrm{~s}, 1 \mathrm{H}), 9.14(\mathrm{~s}, 1 \mathrm{H}), 8.84(\mathrm{~d}, J=4.3 \mathrm{~Hz}, 1 \mathrm{H}), 8.57(\mathrm{~d}, J=5.2 \mathrm{~Hz}, 1 \mathrm{H}), 8.18(\mathrm{~m}$, 1H), $8.09(\mathrm{~m}, 1 \mathrm{H}), 8.04(\mathrm{~s}, 1 \mathrm{H}), 8.00(\mathrm{dd}, J=9.5,1.4 \mathrm{~Hz}, 1 \mathrm{H}), 7.64(\mathrm{~m}, 1 \mathrm{H}), 7.50(\mathrm{~m}, 1 \mathrm{H}), 7.35(\mathrm{~m}, 2 \mathrm{H}), 7.28(\mathrm{~m}, 1 \mathrm{H})$, 7.11 (ddd, $J=8.4,6.8,1.4 \mathrm{~Hz}, 1 \mathrm{H}), 6.83(\mathrm{~d}, J=8.0 \mathrm{~Hz}, 1 \mathrm{H}), 5.10(\mathrm{~m}, 1 \mathrm{H}), 4.90(\mathrm{~m}, 1 \mathrm{H}), 4.61$ (ddd, $J=15.0,11.5,8.2$ $\mathrm{Hz}, 1 \mathrm{H}), 4.47(\mathrm{~m}, 1 \mathrm{H}), 2.97(\mathrm{~m}, 1 \mathrm{H}), 2.90(\mathrm{dd}, J=6.8,2.7 \mathrm{~Hz}, 1 \mathrm{H}), 1.56(\mathrm{~d}, J=6.9 \mathrm{~Hz}, 3 \mathrm{H})$

${ }^{13}$ C NMR (101 MHz, Acetone) $\delta$ 173.24, 169.73, 168.81, 152.68, 150.68, 149.35, 141.69, 131.58, 130.34, 130.29, $127.88,127.08,126.54,126.03,125.97,125.42,125.31,125.04,123.92,123.08,120.10,108.08,59.85,54.71$ (t, $J=$ $32.8 \mathrm{~Hz}), 49.39,37.89(\mathrm{t}, J=23.9 \mathrm{~Hz}), 16.17$.

ESI-MS ${ }^{+}: \mathbf{m} / \mathbf{z}: 519.2[\mathrm{M}+\mathrm{H}]^{+} ; 541.0[\mathrm{M}+\mathrm{Na}]^{+} ; 1059.6[2 \mathrm{M}+\mathrm{Na}]^{+}$

ESI-MS: $\mathbf{m} / \mathbf{z :} 517.2[\mathrm{M}-\mathrm{H}]^{-}$

tert-Butyl 2-(quinoline-4-carboxamido)acetate (48)

tert-Butyl 2-(quinoline-4-carboxamido)acetate was prepared from $\mathbf{4 6}$ and $\mathbf{4 7}$ following general procedure $\mathrm{F}$ and was obtained as a beige amorphous solid.

Yield: $90 \%$

${ }^{1} \mathrm{H}$ NMR (400 MHz, DMSO-d 6 ) $\delta 9.18(\mathrm{t}, J=6.0 \mathrm{~Hz}, 1 \mathrm{H}), 8.99(\mathrm{~d}, J=4.3 \mathrm{~Hz}, 1 \mathrm{H}), 8.27(\mathrm{dd}, J=7.5,0.7 \mathrm{~Hz}, 1 \mathrm{H}), 8.10(\mathrm{~d}$, $J=8.1 \mathrm{~Hz}, 1 \mathrm{H}), 7.83(\mathrm{ddd}, J=8.4,6.9,1.5 \mathrm{~Hz}, 1 \mathrm{H}), 7.69$ (ddd, $J=8.3,6.9,1.3 \mathrm{~Hz}, 1 \mathrm{H}), 7.55(\mathrm{~d}, J=4.3 \mathrm{~Hz}, 1 \mathrm{H}), 4.00(\mathrm{~d}$, $J=6.0 \mathrm{~Hz}, 2 \mathrm{H}), 1.48(\mathrm{~s}, 9 \mathrm{H})$. 
${ }^{13}$ C NMR (101 MHz, DMSO) $\delta$ 168.70, 167.19, 150.31, 147.92, 141.83, 129.95, 129.34, 127.34, 125.58, 124.14, $119.05,81.05,41.92,27.81$.

ESI-MS $:$ m/z: $287.2[\mathrm{M}+\mathrm{H}]^{+}$

To a solution of 48 (1eq.) in dry toluene, Lawesson's reagent (0.55eq.) was added. The reaction was placed under an Ar-atmosphere and left stirring at $110^{\circ} \mathrm{C}$ for $3 \mathrm{~h}$ under reflux conditions. After reaction completion the volatiles were evaporated under reduced pressure. The crude product was further purified using RP-flash chromatography: water:MeOH (95:5) $\rightarrow$ MeOH yielding the title compound as a yellow crystalline solid. ${ }^{1} \mathbf{H}$ NMR (400 MHz, MeOD$\left.\boldsymbol{d}_{4}\right) \delta 8.85(\mathrm{~d}, J=4.4 \mathrm{~Hz}, 1 \mathrm{H}), 8.35(\mathrm{~d}, J=8.4 \mathrm{~Hz}, 1 \mathrm{H}), 8.05(\mathrm{~d}, J=8.5 \mathrm{~Hz}, 1 \mathrm{H}), 7.80(\mathrm{dd}, J=8.1,7.3 \mathrm{~Hz}, 1 \mathrm{H}), 7.65(\mathrm{dd}, J$ $=8.4,7.3 \mathrm{~Hz}, 1 \mathrm{H}), 7.47(\mathrm{~d}, J=4.5 \mathrm{~Hz}, 1 \mathrm{H}), 4.51(\mathrm{~s}, 2 \mathrm{H}), 1.56(\mathrm{~s}, 9 \mathrm{H})$.

${ }^{13}$ C NMR (101 MHz, MeOD) $\delta$ 199.27, 168.52, 151.33, 150.82, 149.01, 131.46, 129.30, 128.54, 126.97, 125.47, $119.40,83.47,48.42,28.30$.

was prepared from 49 following general procedure D and was obtained as a beige amorphous solid.

${ }^{1} \mathrm{H}$ NMR (400 MHz, DMSO-d $)_{6} \delta 11.24(\mathrm{t}, J=5.8 \mathrm{~Hz}, 1 \mathrm{H}), 9.04(\mathrm{~d}, J=4.7 \mathrm{~Hz}, 1 \mathrm{H}), 8.29(\mathrm{dd}, J=9.1,1.2 \mathrm{~Hz}, 1 \mathrm{H}), 8.13$ $(\mathrm{dt}, J=8.4,1.1 \mathrm{~Hz}, 1 \mathrm{H}), 7.90(\mathrm{ddd}, J=8.6,6.9,1.4 \mathrm{~Hz}, 1 \mathrm{H}), 7.74(\mathrm{ddd}, J=8.3,6.9,1.2 \mathrm{~Hz}, 1 \mathrm{H}), 7.55(\mathrm{~d}, J=4.7 \mathrm{~Hz}, 1 \mathrm{H})$, $4.53(\mathrm{~d}, J=5.8 \mathrm{~Hz}, 2 \mathrm{H})$.

${ }^{13}$ C NMR (101 MHz, DMSO) $\delta$ 196.15, 170.97, 168.98 (t, $J=198.7$ Hz) 150.36, 149.06, 145.40, 131.22, 127.96, $127.15,125.77,119.19,118.15(t, J=681.8 \mathrm{~Hz}) 46.49$.

${ }^{1} \mathrm{H}$ NMR (400 MHz, MeOD-d 4 ) $\delta 8.91(\mathrm{~d}, J=4.5 \mathrm{~Hz}, 1 \mathrm{H}), 8.38(\mathrm{dd}, J=8.5,1.3 \mathrm{~Hz}, 1 \mathrm{H}), 8.09(\mathrm{~d}, J=8.6 \mathrm{~Hz}, 1 \mathrm{H}), 7.83-$ $7.80(\mathrm{~m}, 1 \mathrm{H}), 7.79(\mathrm{~d}, J=2.1 \mathrm{~Hz}, 1 \mathrm{H}), 7.70(\mathrm{~d}, J=8.7 \mathrm{~Hz}, 1 \mathrm{H}), 7.62-7.57(\mathrm{~m}, 1 \mathrm{H}), 7.54(\mathrm{~d}, J=4.5 \mathrm{~Hz}, 1 \mathrm{H}), 7.50(\mathrm{dd}, J=$ 8.8, $2.1 \mathrm{~Hz}, 1 \mathrm{H}), 6.26(\mathrm{~d}, J=1.6 \mathrm{~Hz}, 1 \mathrm{H}), 4.73-4.68(\mathrm{~m}, 1 \mathrm{H}), 4.61-4.46(\mathrm{~m}, 1 \mathrm{H}), 3.93-3.83(\mathrm{~m}, 1 \mathrm{H}), 2.52-2.47(\mathrm{~m}$, $2 \mathrm{H}), 2.45(\mathrm{~d}, J=1.3 \mathrm{~Hz}, 3 \mathrm{H}), 2.43-2.32(\mathrm{~m}, 1 \mathrm{H}), 2.24-2.09(\mathrm{~m}, 2 \mathrm{H})$.

${ }^{13}$ C NMR (101 MHz, MeOD) $\delta$ 198.58, 173.20, 167.74, 163.20, 155.62, 154.83, 151.06, 150.60, 148.67, 143.04, $131.68,129.42,128.76,126.91,126.84,119.43,117.31,117.04,113.47,107.82,61.84,48.21,30.81,25.89,21.36$, 18.85 .

ESI-MS $: \mathrm{m} / \mathrm{z}: 501.2[\mathrm{M}+\mathrm{H}]^{+} ; 523.2[\mathrm{M}+\mathrm{Na}]^{+}$

ESI-MS: $\mathbf{m} / \mathbf{z}: 499.1[\mathrm{M}-\mathrm{H}]^{-}$

(S)-N-(4-Nitrophenyl)-1-((quinoline-4-carbonothioyl)glycyl)pyrrolidine-2-carboxamide (52)

(S)-N-(4-nitrophenyl)-1-((quinoline-4-carbonothioyl)glycyl)pyrrolidine-2-carboxamide was prepared from $\mathbf{5 0}$ and $\mathbf{1 7}$ following general procedure $\mathrm{G}$, yielding the title compound as a yellow crystalline solid. 
Yield: $5.9 \%$

${ }^{1} \mathrm{H}$ NMR (400 MHz, MeOD-d $)_{4} \delta 8.85(\mathrm{~d}, J=4.5 \mathrm{~Hz}, 1 \mathrm{H}), 8.35(\mathrm{~d}, J=8.3 \mathrm{~Hz}, 1 \mathrm{H}), 8.21(\mathrm{~d}, J=9.1 \mathrm{~Hz}, 2 \mathrm{H}), 8.04(\mathrm{~d}, J=$ $8.5 \mathrm{~Hz}, 1 \mathrm{H}), 7.85(\mathrm{~d}, J=9.1 \mathrm{~Hz}, 2 \mathrm{H}), 7.80-7.76(\mathrm{~m}, 1 \mathrm{H}), 7.63-7.59(\mathrm{~m}, 2 \mathrm{H}), 7.50(\mathrm{~d}, J=4.5 \mathrm{~Hz}, 1 \mathrm{H}), 4.68(\mathrm{dd}, J=8.6$, $3.6 \mathrm{~Hz}, 1 \mathrm{H}), 3.88-3.83(\mathrm{~m}, 2 \mathrm{H}), 2.38-2.27(\mathrm{~m}, 2 \mathrm{H}), 2.17-2.13(\mathrm{~m}, 2 \mathrm{H}), 0.93-0.88(\mathrm{~m}, 2 \mathrm{H})$.

${ }^{13}$ C NMR (101 MHz, MeOD) $\delta$ 198.92, 173.72, 173.13, 163.13, 151.03, 144.05, 127.09, 125.77, 125.59, 120.62, $119.52,62.56,49.85,49.31,30.70,25.96$.

ESI-MS': m/z: $464.2[\mathrm{M}+\mathrm{H}]^{+}$

ESI-MS: : m/z: 462.1 [M-H] $^{-}$ 


\section{2) Biochemical compound evaluation protocols.}

\subsection{Enzymes and inhibitors}

Recombinant human FAP (rhFAP) was purchased from R\&D. A plasmid containing the human PREP cDNA in the pOT7_hPREP vector (IMAGE: 3614248) was obtained from Dharmacon. The coding sequence was PCR cloned in pET$46 \mathrm{Ek} / \mathrm{LIC}$ (Novagene) with an N-terminal hexahistidine tag using standard techniques. Human PREP was expressed in BL21(DE3) cells and purified using immobilized Co-chelating chromatography (GE healthcare) followed by anionexchange chromatography on a $1 \mathrm{ml}$ Mono Q column (GE healthcare). Human dipeptidyl peptidase IV (DPP IV) was purified from human seminal plasma as previously published. ${ }^{1}$ Gateway-entry clones for human DPP8 and DPP9 were purchased from Dharmacon (Accession numbers DQ891733 and DQ892325, respectively). For transfection and expression of the DPP8 and DPP9 in Sf9 insect cells the N-terminal BaculoDirect kit from LifeTechnologies was used. The enzymes were purified using immobilized Ni-chelating chromatography (GE healthcare), followed by anionexchange chromatography using a $1 \mathrm{~mL}$ Mono Q (GE healthcare). The inhibitors UAMC-1110 and KYP-2047 were synthesized in-house.

\subsection{Kinetic characterization of AMC- and pNA-based molecules.}

Initial rate measurements were performed with pNA and AMC substrates in 96-well half area plates (Greiner Bioone) at $37{ }^{\circ} \mathrm{C}$ in an Infinite ${ }^{\mathrm{TM}} \mathrm{M} 200$ reader (Tecan Benelux) in an end volume of $100 \mu \mathrm{L}$ (sample volume $5 \mu \mathrm{L}$ ). Chromogenic substrates were measured kinetically at $405 \mathrm{~nm}$, and fluorogenic substrates at an excitation wavelength of $350 \mathrm{~nm}$ and an emission wavelength of $450 \mathrm{~nm}$. Fluorescence intensity was correlated to a calibration curve of AMC, measured under the same assay conditions. As a blank, the assay buffer was used instead of the enzyme. Assay buffers were for FAP a 50 mM Tris- $\mathrm{HCl}$ pH 7.5, 140 mM NaCl buffer, for PREP a 0.1 M Tris- $\mathrm{HCl}$, pH 7.5, $1 \mathrm{mM}$ EDTA, $3 \mathrm{mM}$ dithiothreitol (DTT) buffer and for the DPPs $50 \mathrm{mM}$ Tris-HCl pH 8.3. Plates were pre-heated at 37 ${ }^{\circ} \mathrm{C}$.

$\mathrm{K}_{\mathrm{m}}$ and $\mathrm{k}_{\mathrm{cat}}$ were determined by plotting the initial velocities of product formation $\left(\mathrm{v}_{\mathrm{i}}\right)$ over enzyme concentration $\left(E_{0}\right)$ against the different substrate concentrations $([S])$. The highest concentration for each substrate was the limit of solubility of that specific substrate and at least 6 different concentrations were used. All the stock solutions of the substrates were dissolved in dimethylsulfoxide (DMSO). For FAP, the final concentration of DMSO was $1 \%$ for all used substrate concentrations. The data were then fitted to the Michaelis-Menten equation by non-linear regression analysis using GraphPad Prism 6 according to the following equation $\frac{v_{i}}{E_{0}}=\frac{k_{c a t} *[S]}{K_{m}+[S]}$. For certain substrates kinetic parameters could not be computed because saturation could not be achieved, in this case linear regression was used, where the slope represents $\mathrm{K}_{c a t} / \mathrm{K}_{\mathrm{m}}$ since $\mathrm{K}_{\mathrm{m}}>[\mathrm{S}]$. In addition, a substrate demonstrated substrate inhibition at higher substrate concentrations, in this case the data was fitted to the following equation $\frac{v_{i}}{E_{0}}=\frac{k_{\text {cat }} \cdot[S]}{K_{m}+[S] \cdot\left(1+\frac{[S]}{K_{i}}\right)}$. 


\subsection{Kinetic characterization of 4-AN-based molecules}

The cleavage of the 4-AN substrates by FAP and/or PREP was evaluated using an in-house developed UPLC-MRM MS assay in which the residual substrate concentration is measured at specific time points.

Instrument, reagents, buffer solutions and calibrators:

UPLC analysis was performed using a Waters acquity $\mathrm{H}$-Class UPLC system including a Waters TQD ESI mass spectrometer and a Waters TUV detector coupled to MassLynx 4.1 software. LC-MS grade MeOH, -water with $0.01 \%$ formic acid, -water and - DMSO were purchased from Thermo Fischer Scientific.

Assay buffers consisted of a $50 \mathrm{mM}$ Tris- $\mathrm{HCl} \mathrm{pH} \mathrm{7.5,140} \mathrm{mM} \mathrm{NaCl} \mathrm{buffer} \mathrm{for} \mathrm{FAP} \mathrm{and} \mathrm{a} 0.1 \mathrm{M} \mathrm{Tris-HCl,} \mathrm{pH} 7.5,1 \mathrm{mM}$ EDTA, 3 mM dithiothreitol (DTT) buffer for PREP. Primary stock solutions for calibration curves of substrates $6 \mathbf{h}-\mathbf{k}$, each at a concentration of $10 \mathrm{mM}$, were prepared separately in DMSO. Using FAP buffer and PREP buffer, a calibrator series (31.25 nM, 62.5 nM, 125 nM, 250 nM, 500 nM, 750 nM, 1000 nM, 2000 nM, 3000 nM and 4000 $\mathrm{nM}$ ) of substrates $\mathbf{6 h - k}$ was prepared in duplo for the FAP and PREP assays respectively.

Sample preparation:

Stock solutions of substrates $\mathbf{6 h - k}$, each at a final concentration of $10 \mu \mathrm{M}$, were prepared in two steps and in duplo from their primary stock solutions in DMSO, each at a concentration of $100 \mathrm{mM}$. 7,5 $\mu \mathrm{L}$ of enzyme (final concentration $2.6 \mathrm{nM}$ FAP or $5.2 \mathrm{nM}$ PREP) or buffer was added to $142.5 \mu \mathrm{L}$ of substrate stock solution. Samples were incubated at $37^{\circ} \mathrm{C}$ in a Thermomixer. $10 \mu \mathrm{L}$ of sample was taken at 0-, 2-, 4-, 6-, 8-, 10-, 15-, 20-, 25- and 30 minutes. $90 \mu \mathrm{L}$ of water with $1 \%$ formic acid was added to deactivate the enzyme and the samples were stored at $-80^{\circ} \mathrm{C}$ until analysis.

UPLC MRM MS analysis:

$3 \mu \mathrm{L}$ of sample was injected at a flow of $0.3 \mathrm{~mL} \cdot \mathrm{min}^{-1}$. Chromatographic separation was performed using a Waters Xselect CSH C18 Column XP $(2.5 \mu \mathrm{m} 2.1 \times 75 \mathrm{~mm})$ operated at $40^{\circ} \mathrm{C}$. Solvent A consisted of water with $0.05 \%$ formic acid and solvent $\mathrm{B}$ consisted of $\mathrm{MeOH}$. Optimised separation conditions were obtained by using the following gradient method: a flow of $0.3 \mathrm{~mL} \cdot \mathrm{min}^{-1}$ was used. A gradient was run from $97 \% \mathrm{~A}$ and $3 \% \mathrm{~B}$ to $10 \% \mathrm{~A}$ and $90 \% \mathrm{~B}$ in $7.5 \mathrm{~min}$. Then in $2.5 \mathrm{~min}$ to $97 \% \mathrm{~A}$ and $3 \% \mathrm{~B}$ over $2.5 \mathrm{~min}$ followed by $2 \mathrm{~min}$ of isocratic run at $97 \% \mathrm{~A}$ and $3 \% \mathrm{~B}$. Detection was consecutively performed by using ESI- mass spectrometry in multiple reaction monitoring (MRM) mode. The TQD was operated in electrospray positive ionisation mode at $140{ }^{\circ} \mathrm{C}$. For the fitting of the data it was assumed that $[S] \ll<K_{m}$, which allows to rewrite the Michaelis-Menten equation as a first order reaction with the following equation $S=S_{0} \cdot e^{-k^{\prime} . t}$ with $k^{\prime}=\frac{k_{c a t}}{K_{m}} \cdot E_{0}$ and $S_{0}=$ the substrate concentration at $\mathrm{t}=0 \mathrm{~min}$. 


\section{3) Cellular evaluation of 4-AN-based molecules}

\subsection{Cell culture and transfection}

HEK293T cells were cultured in DMEM supplemented with $10 \% \mathrm{FCS}, 100 \mathrm{U} / \mathrm{ml}$ penicillin and $100 \mathrm{\mu g} / \mathrm{ml}$ streptomycin in 8-well Millicell EZ Slides (Merck). Cells were seeded at $1.5 \times 10^{5}$ cells per well the day before transfection. A gateway-entry clone for human FAP was purchased from Dharmacon (Accession number DQ891423) and cloned in the pDEST40-vector (ThermoFisher) using the Gateway LR enzyme II mix (ThermoFisher) following the manufacturer's instructions. HEK293T cells were transfected at 80-90 \% confluency with the PDEST40-hFAP-vector using the Lipofectamine 2000 transfection reagent (ThermoFisher) in a 1:3 ratio of DNA/ Lipofectamine 2000. Cells were used 48 hours after transfection for histochemical activity assay. The empty PDEST40-vector transfected in HEK293T cells was used as a control. Transfection was evaluated by measuring the FAP- and PREP-activity in the lysate supernatant of HEK293T cells, using a protocol reported recently (Bracke et al. The Development and Validation of a Combined Kinetic Fluorometric Activity Assay for Fibroblast Activation Protein Alpha and Prolyl Oligopeptidase in Plasma. Clin. Chim. Acta 2019, 495, 154-160). Measured FAP and PREP activities in cells obtained from six orthogonal transfection experiments, are shown in Figure S-1.

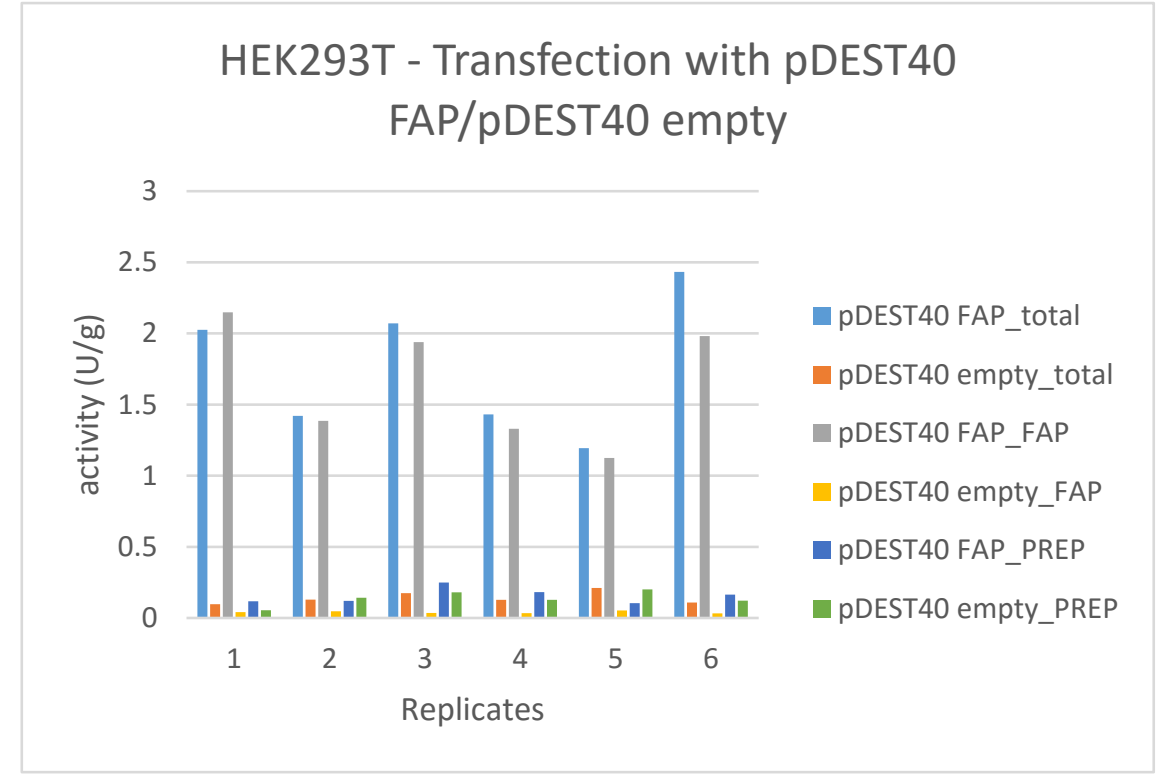

Figure S-1 Z-Gly-Pro-AMC processing in cell lysate supernatant. ' $P D E S T 40$ FAP' refers to cells transfected with a hFAP vector; 'pDEST40empty' refers to cells transfected with an empty vector; '_total' refers to the total [FAP+PREP] activity measured in the supernatant; '_FAP' refers to FAP activity measured in the supernatant and '_PREP' refers to PREP activity measured in the supernatant.

Briefly, cells were lysed 48 hours after transfection in enzymatic lysis buffer (1\% octylglucoside, 10 mM EDTA, 70 $\mu \mathrm{g} / \mathrm{mL}$ aprotinin, $50 \mathrm{mM}$ Tris- $\mathrm{HCl} \mathrm{pH} \mathrm{8.3)} \mathrm{for} 1$ hour with frequent agitation and centrifuged at $12000 \times \mathrm{g}$ for 10 
minutes at $4{ }^{\circ} \mathrm{C}$. The resulting supernatant was used in the activity measurement. Z-Gly-Pro-AMC (Bachem) was used as a substrate at a final concentration of $266 \mu \mathrm{M}$. AMC release was measured kinetically at an excitation wavelength of $380 \mathrm{~nm}$ and an emission wavelength of $465 \mathrm{~nm}$ in an Infinite ${ }^{\mathrm{TM}} \mathrm{M} 200$ reader at $37^{\circ} \mathrm{C}$. To differentiate between FAP- and PREP-activity, the FAP-selective inhibitor UAMC-1110 and PREP-selective inhibitor KYP-2047 were used, both at $50 \mathrm{nM}$ as a final concentration. Assay buffer was $0.1 \mathrm{M}$ Tris- $\mathrm{HCl}$ pH 8, $300 \mathrm{mM} \mathrm{NaF,} 1 \mathrm{mM}$ EDTA, $50 \mathrm{mM}$ salicylic acid, $1 \mathrm{mM} \mathrm{NaN}_{3}$. Fluorescence intensity was correlated to a calibration curve of AMC measured under the same assay conditions.

\subsection{Cellular evaluation protocols and results for compound 6 i.}

FAP-transfected HEK293T cells were used for the evaluation of the 4-aminonaphthol based substrates $6 \mathbf{h}$ and $6 \mathbf{i}$ (data obtained for $6 \mathrm{~h}$ were already reported in the manuscript text). Cells were fixed in acetone at $-20{ }^{\circ} \mathrm{C}$ for 10 minutes. Afterwards cells were washed with $0.1 \mathrm{M}$ phosphate buffer $\mathrm{pH} 7.8$ and pre-incubated for 5 minutes with DMSO, 250 nM UAMC-1110 or 250 nM KYP-2047 in the phosphate buffer at $37{ }^{\circ} \mathrm{C}$. In the next step, this was replaced with the different substrates, each at $250 \mu \mathrm{M}$, in a $250 \mu \mathrm{M}$ nitroblue tetrazolium (NBT, Sigma)-buffer solution and incubated for 5 hours at $37^{\circ} \mathrm{C}$. The final concentration of DMSO is $1 \%$ in these assay conditions. After this incubation period, the cells were washed again with buffer and fixed with $10 \%$ formaline-solution for 30 minutes. After washing with buffer and distilled water, the cells were counterstained for 5 minutes with $0.5 \%$ methyl green solution. Subsequently, the cells were washed and dehydrated in rising concentrations of ethanol, cleared in xylene and mounted with Entellan (Merck). The empty pDEST40-vector served as a control. Cellular evaluation data for compound $\mathbf{6 i}$ are shown in Figure S-2 and are comparable to data obtained for $\mathbf{6 h}$. A brightfield/epifluorescence microscope (Zeiss Axiophot, Carl Zeiss, Jena, Germany) at magnification 10x was used to image the sections. Images were acquired and processed using DP Controller (Olympus).

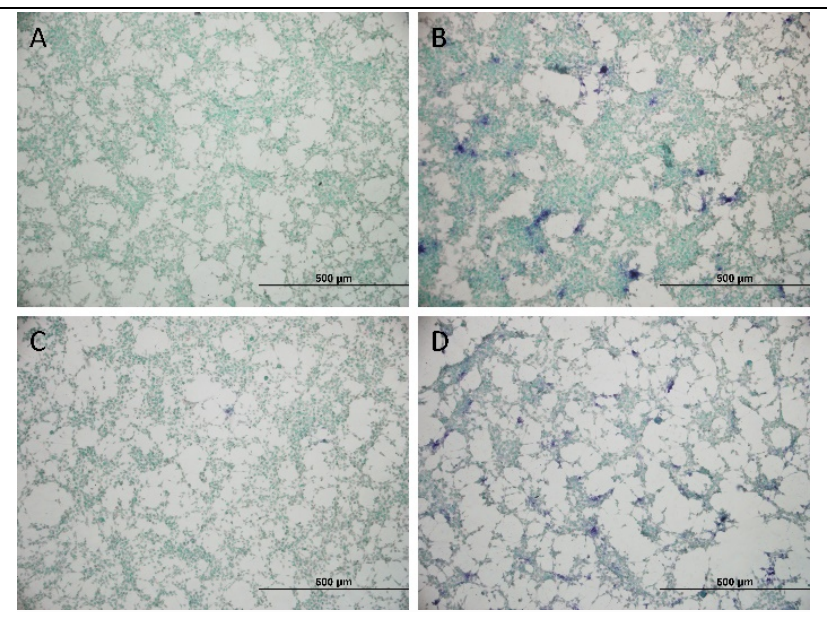

Figure S-2. FAP-Activity staining in HEK293T cells with 6i. Panel A: cells transfected with empty pDEST40-vector and treated with 6i; Panels B-D: cells transfected with pDEST40-hFAP-vector, treated with 6i (B), with 6i + FAPinhibitor 5/UAMC-1110 (C) or with 6i and PREP-inhibitor KYP-2047 (D). 